Portland State University

PDXScholar

Spring 5-26-2016

\title{
"That's the test?" Washback Effects of an Alternative Assessment in a Culturally Heterogeneous EAP University Class
}

Abigail Bennett Carrigan

Portland State University

Follow this and additional works at: https://pdxscholar.library.pdx.edu/open_access_etds

Part of the Bilingual, Multilingual, and Multicultural Education Commons, and the Educational Assessment, Evaluation, and Research Commons

Let us know how access to this document benefits you.

\section{Recommended Citation}

Carrigan, Abigail Bennett, "'That's the test?" Washback Effects of an Alternative Assessment in a Culturally Heterogeneous EAP University Class" (2016). Dissertations and Theses. Paper 2994. https://doi.org/10.15760/etd.2995

This Thesis is brought to you for free and open access. It has been accepted for inclusion in Dissertations and Theses by an authorized administrator of PDXScholar. Please contact us if we can make this document more accessible: pdxscholar@pdx.edu. 


\title{
"That's the test?" Washback Effects of an Alternative Assessment in a Culturally Heterogeneous EAP University Class
}

\author{
by
}

Abigail Bennett Carrigan

A thesis submitted in partial fulfillment of the requirements for the degree of

\author{
Master of Arts \\ in \\ Teaching English to Speakers of Other Languages
}

Thesis Committee:

Nike Arnold, Chair

Errin Beck

Alissa Hartig

Portland State University

2016 


\begin{abstract}
To determine learner attitudes toward an alternative assessment, additional washback effects, and possible relationships between cultures of learning and learner attitudes, a mixed methods study was conducted in an advanced multicultural EAP (English for Academic Purposes) class in the USA, where a poster project was implemented as a summative assessment. Qualitative and quantitative data from a preand post-test questionnaire as well as classroom observations and an interview with the instructor were used to investigate learners' attitudes towards the assessment. The twenty-four participants representing five cultures of learning from the Middle East, South America and Southeast Asia expressed largely positive attitudes prior to completing the poster project. After the project presentations, there was minimal change in their attitudes. The researcher identified six positive and three negative washback effects of the poster project: positive attitudes toward the poster project, self-confidence, accurate identification of the learning goal, awareness of learning, community building and cultural exchange, deeming the assessment useful, negative attitudes toward the poster project, misidentification of the learning goal, and deeming the assessment not useful. Although there was no relationship between participants' cultures of learning and their attitudes toward the poster project, their prior experience with alternative assessments may be related to their attitudes.
\end{abstract}


Table of Contents

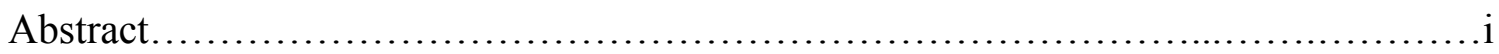

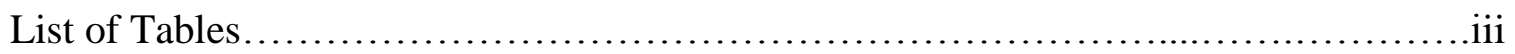

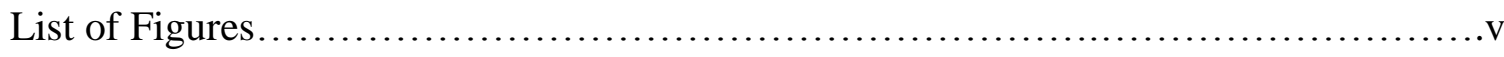

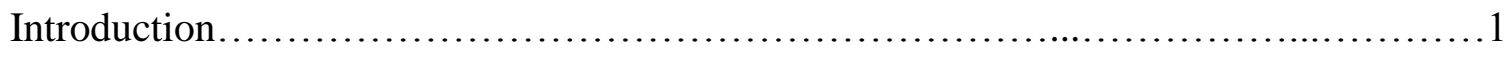

Literature Review...........................................................

Research Purpose and Questions........................................... 15

Methodology ............................................................. 16

Data Analysis............................................................ 33

Results.................................................................. 36

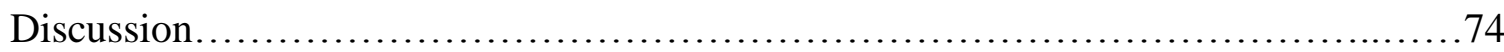

Conclusion............................................................ 83

References............................................................. 89

Appendices

A: Pre-Test........................................................... 92

B: Post-Test....................................................98

C: Instructor's Interview Questions.................................. 103

D: Assignment and Rubric............................................ 104

E: Pre-Test Open-Ended Responses.................................... 108

F: Post-Test Open-Ended Responses..................................118 


\section{List of Tables}

Table 1 Number of Participants by Culture of Learning and Enrollment.

Table 2 Participants' Previous Experience with Alternative Assessments in Their Home Countries.

Table 3 Participants' Previous Experience with Alternative Assessments in the United States. .21

Table 4 Frequency of Participants' Previous Experience with Alternative Assessments at Home. 22

Table 5 Frequency of Participants' Previous Experience with Alternative Assessments in the US. .23

Table 6 Rubric for AAR Poster Project..................................................................25

Table 7 Breakdown of the Likert-Scale Items on the Pre-test.....................................28

Table 8 Breakdown of the Likert-Scale Items on the Post-test......................................30

Table 9 Items from the Attitude Domain on the Pre-Test...........................................45

Table 10 Participants' Mean Attitude Scores on the Pre-Test.........................................47

Table 11 Participants' Responses to the Question: Describe how you feel about doing this assignment. Would you rather take a test? Why or why not?.

Table 12 Participants' Responses to the Question: Will giving a presentation be useful

for your learning? How or how not?

Table 13 Participants' Perceived Attitude Changes toward the Poster Project Based on the Question: Has your attitude about this poster project changed in any way? If so, how? 
Table 14 Participants' Attitude Change Directions from Pre-Test to Post-Test............. 58

Table 15 Participants' Mean Attitude Scores on the Post-Test........................................59

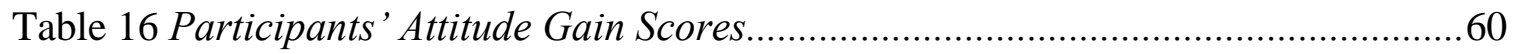

Table 17 Participants' Perceived Learning Goals According to Post-Test Open-Ended

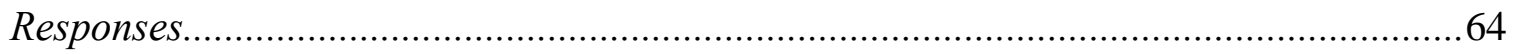

Table 18 Participants' Claims of Learning According to Post-Test Open-Ended

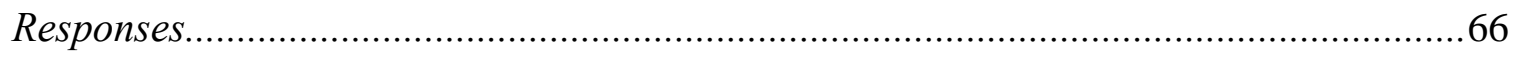

Table 19 Participants' Innovativeness Gain Scores................................................... 71

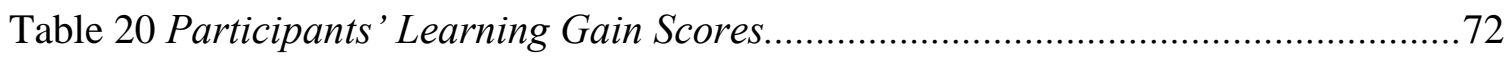




\section{List of Figures}

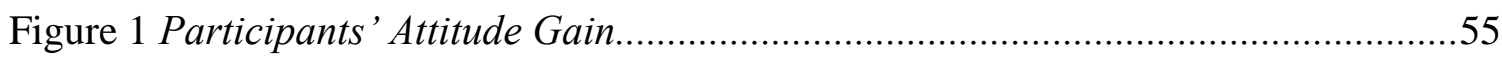




\section{Introduction}

As a natural test taker, I grew up happily anticipating "test Friday."

Consequently, I grew up with poor study habits. During the course of my graduate studies, I was exposed to an array of alternative assessments including peer assessment, self-assessment, group projects, and an e-portfolio, all of which have challenged my knowledge and academic abilities. More than that, this exposure required an adjustment in my schema of the classroom, my peers, and assessment in general as well as a cognitive adjustment of my values and expectations. Fortunately, I shared the same cultural background and similar educational background with most of my peers and faculty. But what if I had not? How would that have changed my experience with alternative assessments?

This thesis is meant to address the effects of alternative assessments on student learning in a culturally heterogeneous English as a Second Language (ESL) classroom. Most of the research investigating the effects of assessment on learning, washback, has focused on large-scale high stakes tests or other university entrance examinations. Although there has been some exploration using low-stakes classroom assessment systems, teachers have been studied more than students (Green, 2013, p. 43). This paper intends to fill this gap by focusing on students who are participating in a classroom-based assessment. After a review of the literature describing alternative assessments and washback, I explain the methods I used to answer the research questions posed at the end of the literature review. 


\section{Literature Review}

There is currently a movement away from the traditional testing model of an individual assessment conducted with pencil and paper. Any method of assessing students that is not a traditional paper and pencil test is considered to be a type of alternative assessment. The traditional model is described by Lytle and Wolfe (1989) as "the historically dominant mode of Western literacy, literacy-for-school, or the 'essayist' tradition" and is contrasted by alternative assessments (as cited in Balliro, 1993, pp. 558559).

As second language (L2) instruction has shifted toward more communicativeoriented outcomes for L2 teaching to prepare learners for practical language use in an increasingly globalized world (Johnson, 2009, p. 80), types of assessment may also need to shift. Several researchers have identified some alternative assessments that are being implemented in the classroom, many of which include problem solving, real world contexts, and tasks that are more closely related to the daily activities of the class than the traditional testing format (see, e.g., Brown \& Hudson, 1998; Burkšaitienė \& Teresevičienè, 2008; Hafner \& Ulanoff, 1994).

Brown and Hudson (1998) compiled a list of characteristics that distinguish alternative assessments from traditional assessments (p. 653). To name a few, assessments must require students to perform, create, produce, or do something; they must use real-world contexts or simulations; they should allow students to be assessed on their everyday in-class activities; and they should be multiculturally sensitive (Brown \& Hudson, 1998, p. 654). (For a more exhaustive list, please see Brown and Hudson, 
1998.) After discussing some advantages and disadvantages to different types of assessment, Brown and Hudson (1998) recommend that procedures such as portfolios, diaries, self-assessments, and peer assessments be referred to as alternatives in assessment rather than alternative assessments because these types of assessments are simply new developments in a long tradition of language assessment (p. 657). Balliro argued for a more descriptive term than alternative assessment, such as congruent assessment, suggesting an alignment between the goals of the teachers and students and the assessments employed to measure their achievement of them (1993, p. 560). For the purpose of this study, alternative assessment will be used to describe any non-traditional method of assessment, that is, anything that is not a paper and pencil test.

However, in this important shift toward more alternative assessments, we need to consider the role that culture plays in student attitudes and educational systems, in order to understand how students may feel about and ultimately engage with alternative assessments. Culture plays an important role in student learning and students' attitudes about assessments. The teacher of a culturally homogeneous classroom is able to manage the expectations of the learners' home culture, however, the teacher of a multicultural ESL classroom is responsible for instructing students from a variety of cultural and educational backgrounds. "Numerous contrasts characterize learning across cultures, and many of these have implications for assessment" (Kopriva, 2008, p. 23). Project learning and other performance-based assessments employ the teachers as facilitators and mentors while the students take an active role in their learning processes promoting creativity, critical thinking, and experiential learning (Barfield, 2003; Bourner et al., 2001) (as cited 
in Burkšaitienė \& Teresevičienė, 2008). ESL students in the U.S. operate according to their own cultural values while in the context of another, foreign, majority culture. The majority culture of the U.S., identified by Kopriva (2008) as college-educated and western European, values independence, risk-taking, and creative thinking (p. 23). In an ESL classroom at an American university, it is likely that only some students share the same cultural background while the instructor may not share the same cultural background with any of their students. According to Porto (2010), language educators require the awareness, knowledge, procedures, and strategies that will allow them "to focus on the complexity that the integration of language and culture involves in the practical reality of the classroom" (p. 52). Therefore, instructors should consider the adjustment their ESL students are making to life in an unfamiliar place and possibly an unfamiliar educational system.

Ilieva (2001), herself an English language learner and immigrant, concluded that language learners should be given the opportunity to "name their own experience" in their new culture (p. 11). Thus, teachers should use a range of assessments that are relevant to the world the students are interacting with as well as to what they are doing in the classroom itself. However, whatever activities and assessments are used in the classroom, their cultural meanings must be negotiated (Ilieva, 2001, p. 2). According to Porto (2010), "individuals in a given culture draw on multiple resources to make sense of the world and to make sense of oral and written texts" (p. 47).

In order to hear perspectives of the university classroom testing practices, Teemant (2010) conducted a series of interviews with 13 international students studying 
at an American university. The interviewees were asked a number of questions, the answers to which revealed testing problems related to context, culture, and language. Regarding the cultural dimension of testing, students identified several differences between the manner of tests in the U.S. and their home-country systems. In fact, two thirds of the ESL students revealed in interviews that testing in American systems was different from their home-country. Students were surprised by a higher frequency of testing as well as an expectation to express personal opinions as well as facts on tests (p. 93). Test format was a particular area of uncertainty among students as "the U.S. system has alternatives in testing formats that are unfamiliar to ESL students" (p. 94). According to Teemant (2010), the expectations of the test format depended on each student's previous educational experience in their home country (p. 94).

In an increasingly globalized world, it is important to look at cultural diversity. The role of diversity in the ESL classroom has been left out of the research about alternative assessments. Researchers who have explored the effects of alternative assessment implementation on student learning in their own classrooms have had culturally homogenous classrooms (see, e.g., Burkšaitienė \& Teresevičienė, 2008; Hung, 2012; Lambert, 2008; Suzuki, 2009). The teacher of a culturally homogenous classroom, if the teacher has the opportunity to experiment with the methods of teaching, learning, and assessment used in the classroom, is in a position to address the cultural issues and adapt the methods and assessment for their unique classroom. As mentioned above, this is rarely the case for an ESL teacher, which is why it is important to explore the attitudes 
of students toward different types of assessment. The present study was designed to do that.

\section{Washback Effect}

Washback refers to the effect that assessment has on teaching and learning. The phenomenon has also been called backwash, test impact, measurement-driven instruction, curriculum alignment, and test feedback (Brown \& Hudson, 1998, p. 667). More recently, an argument has been made that washback is the interaction between testing, teaching, and learning (Green, 2013, p. 48). Assessment can have either a positive or negative effect on teaching and learning (Bachman \& Palmer, 1999; Brown \& Hudson, 1998; Cheng \& Watanabe, 2004; Messick, 1996). Otherwise put, "washback is usually evaluated as taking a beneficial or damaging direction to the extent that it encourages or discourages forms of teaching or learning intended by the test developers" (Green, 2013, p. 40).

Assessment, teaching, and learning are inevitably tied; therefore, "a well-designed test should encourage good teaching" while "a poorly designed test will tempt teachers and learners into practices that have limited value in relation to long-term learning goals" (Green, 2013, p. 41). Bailey (1999) asserted that improved learning is the resultative product of beneficial washback (as cited in Nkosana, 2009, p. 65). According to Messick (1996), in order for optimal positive washback to be achieved, there should be little to no difference between the activities involved in language learning and those involved in test preparation. Pearson (1988) determined that the washback effects of assessments will be positive if they are beneficial and encourage desired changes on teaching, learning, and 
curriculum (as cited in Hung, 2012, p. 27); and Green (2013) observed that the differences between test taking processes and real-world language use are proportional to the risk of damaging, or negative, effects on learning (p. 41). However, studies have shown that "washback is not a simple or straightforward phenomenon that conforms neatly to popular notions about the effects of tests on language learning" (Brown \& Hudson, 1998, p. 667). Assessment outcomes are also impacted by characteristics of the test and its test taker, the strategies employed by the test taker, and the resultative inferences and decisions made by the test (Cheng, 2005, p. 25); therefore, language test scores represent a complex of multiple influences and cannot be interpreted simplistically (Cheng \& Watanabe, 2004, p. 5).

The complexity of washback effects are underscored by Alderson and Wall's (1993) series of plausible hypotheses for washback as alternatives to their Washback Hypothesis which simply states that tests influence teaching (as cited in Alderson \& Hamp-Lyons, 1996, p. 281). Of the fifteen posed hypotheses, Alderson and Wall's (1993) 2nd, 10th, and 11th washback hypotheses should be kept in mind for the purposes of this study:

2. A test will influence learning.

10. A test will influence the degree and depth of learning.

11. A test will influence attitudes to content, method, etc. of teaching/learning. (as cited in Alderson \& Hamp-Lyons, 1996, pp. 281-282)

With these hypotheses in mind, teaching is not the only thing that might be influenced by assessment. Learners, their depth of learning, and their attitudes toward content, teaching 
methods, and even assessment types, merit attention. The focus of this study is on washback as manifested in the attitudes of learners toward an assessment measure.

Our cultural backgrounds inform our beliefs and value systems which have, in turn, been the context of our socialization into education systems. In these systems, we become familiar with certain types of assessment practices which are imbued with value. "Cultures of learning, as a concept, suggests that learning is cultural: Members of different cultural communities may have different preferences, expectations, interpretations, values, and beliefs about how to learn or how to teach" (Cortazzi \& Jin, 2013 , p. 1). When students from different cultures of learning are learning together in one classroom, the differences in their cultures, values, and consequential attitudes toward learning and teaching must be taken into consideration to foster student learning. Just as the teacher's knowledge and beliefs are embedded in their culture, so their values, assumptions, and attitudes are embedded in their classroom (Johnson, 2009, p. 17). But their students bring their own to the classroom. A student from a culture of learning with a contrastive set of values may not respond positively to the assessment practices that are built into the framework of the school's majority culture.

The attitude of the learner is an important factor in the outcome of learning and is therefore related to washback. According to Muñoz and Álvarez (2010), "the research literature suggests that beliefs and practice are inevitably related" (p. 46). It has been argued by Cheng and Curtis (2004) that when teachers and learners have a positive attitude toward the assessment, positive washback effects will be generated (as cited in Hung, 2012, p. 27). An assessment measure can influence the perceptions and attitudes 
of the test taker toward their work (Bailey, 1999; Hughes, 1993) (as cited in Nkosana, 2009, p. 65).

In Nkosana (2009), teachers and students completed questionnaires which were designed to elicit information about how the lack of a speaking component on a high stakes exam influenced the perceptions and attitudes of the participants toward the teaching and learning of speaking. Nkosana associates perceptions with words like impression, conception, and understanding, and attitudes with words like, thoughts, beliefs, and feelings. This leads me to believe that Nkosana's distinction between the terms is about direction; perceptions are what we understand about what is outside or around us, whereas attitudes are beliefs generated from within a person. The distinction between perceptions and attitudes is important for washback because, while attitudes affect people's behavior, perceptions may not necessarily do so, and therefore, attitudes are more likely to be associated with washback than perceptions. Although the findings revealed that teachers perceived that the addition of a speaking test would have a positive washback effect, the lack of a speaking component on the version of the exam in question was not shown to have negatively affected the attitudes of teachers or students toward speaking skills in general. Nkosana supposed that this may be due in part to the status English has maintained as a language of power. Nkosana (2009) demonstrated how a variety of factors, including the status of the language, affect learner attitudes and the role that attitudes play in washback.

Alderson and Hamps-Lyons (1996) compared TOEFL preparation courses with other ESL courses in order to look at different types of washback effects on teaching. 
For their qualitative study, they conducted interviews with students as well as teachers. Part of their research involved exploring teachers' attitudes toward teaching TOEFL and learning. They noticed that most teachers had a negative attitude toward the TOEFL in general as well as toward teaching a preparatory class for it. After observing two teachers in their TOEFL preparation courses as well as other ESL courses taught by them, their findings suggested that the amount and type of washback will vary according to the following factors: the status of the test, the extent to which the test is counter to current practice, the extent to which teachers and materials developers think about appropriate methods for test preparation, and the extent to which teachers and materials developers are willing and able to innovate. The same relevance teachers' attitudes toward an assessment had in this washback study on teaching, students' attitudes toward an assessment have in any washback study on learning. Washback studies should include those that are teacher-centric and consider washback effects on teaching as well as those that are student-centric and consider washback effects on learning.

More washback studies should consider washback effects on learning rather than teaching. In 2008, Burkšaitienè and Teresevičienè initiated a project in which alternative methods, such as group learning and writing portfolios, were integrated with the traditional educational methods in an English for Law class in Lithuania. The aim of the study was to look at the assessment's effectiveness from the learner's perspective. Students were given agency in choosing their groups as well as the topics for their group projects. They also helped the teachers determine the assessment criteria, allowing them to voice what they believed was important in their work and develop personal standards 
and responsibility for their work. Students also completed two Likert-scale questionnaires: the first looked at the students' attitudes toward the methods and assessment used in the class, and the second measured the effectiveness of and the students' satisfaction with the alternative methods used in the course. Although it is possible the students' agency in selecting the assessment types and their criteria impacted the positive attitudes toward the assessments, it is likely that there was a reason these types of alternative assessments were appealing to the students. The major findings of the study concluded that the integration of alternative methods of learning and assessment was successful, leading the researchers to determine that their integration is useful in teaching and learning English for Specific Purposes (ESP) at a college level. It is likely that the integration of alternative methods of learning and assessment will be successful and useful in an English for Academic Purposes (EAP) class, because going to college is a specific purpose for which the participants in this study are learning English.

In another ESP class, Lambert (2008) was influenced by considerations of authenticity and washback when he decided to have his Japanese English as a Foreign Language (EFL) learners give oral presentations with a visual aid as their final assessment. Integrated into an EAP course for Engineering majors, it was "an authentic and communicative activity both for professional and academic purposes" (Underhill, 1987, p. 47) (as cited in Lambert, 2008). Students worked in groups to develop a poster which they would present together at the end of the term. The researcher believed the visual aid reduced stress by providing support for the speakers as well as the listeners during the presentations. There were layers of alternative assessments built into the 
assignment including group work, poster design, oral presentation, and peer evaluation. Over the course of four class sessions, the students took turns presenting their posters to other groups of students who rotated around the room listening to the presentations. The listening students then provided immediate feedback to their peers by filling out a brief questionnaire. To accommodate this procedure, students had to arrive early to the classroom to move the desks to the edge of the classroom and set up their presentations. Feedback from the students afterward was "generally positive...despite expressing initial misgivings about the task" (p. 7). The researcher believed that showing posters done by previous groups gave students a clear picture of what the students were trying to achieve. Lambert concluded that poster presentations can provide a useful assessment of students' oral proficiency among learners in different fields of study by evaluating performance against a set of clearly defined criteria (p. 9). Although student attitudes at the beginning of the task may have predicted negative washback effects, the assessment yielded positive washback effects. Because Lambert provided students with sufficient support through the visual aid, peer support, and immediate feedback, students' attitudes were positively changed over the course of the assessment.

Another example of a teacher providing students with support in an effort to obtain positive washback is Hung (2012), which looked at washback concerning the use of e-portfolios in a teacher training program based in Taiwan. Portfolios provide learners with the opportunity to monitor their own progress, select the artifacts that are included, and take responsibility for meeting learning goals. The data for the study was collected through interviews, observations, and document analysis of the artifacts included in the e- 
portfolios. The findings of the study showed both positive and negative washback effects. Hung counted the following as some of the positive washback effects of the eportfolios: building a community of practice, facilitating peer learning, enhancing learning of content knowledge, promoting professional development, and cultivating critical thinking. Negative washback effects of the assessment included anxiety from larger audiences and resistance to technology. Hung believed it was crucial that preservice teachers realize their peers as learning resources as opposed to critical judges ( $\mathrm{p}$. 33). Some of the types of effects which Hung categorized as positive and negative washback are related to the attitudes of the learner, which affirms the importance of consideration of learners' attitudes when looking at washback.

According to Green (2013), washback studies have revealed considerable variability in the effects of tests on teaching and learning suggesting that the variables interacting and shaping washback are complex, making washback effects highly variable and contextualized (p. 44). Considering the relationship between assessment, teaching, and learning, researchers have wondered whether curriculum should be born from testing rather than vice versa in order to use the washback phenomenon to the advantage of the primary participants in education: the teacher and the learner. Brown and Hudson (1998) advises:

If teachers consider how [course] objectives will be assessed or observed at the end of the course and follow through by using the assessment format that best matches each objective, they will be helping to create a strong relationship 
between the assessment procedures and the objectives and therefore helping to produce a positive washback effect. (p. 668)

There are several gaps in the research concerning washback, classroom-based assessments, and learners. Washback research has so far primarily been concerned with the side of test development, including test developers and teachers. As teachers have been a primary focus of washback research, there is a more noticeable lack of research concerning learners (Green, 2013, p. 43). "Research needs to be done on the effects of classroom assessment on the depth and degree of student learning” (Muñoz \& Álvarez, 2010, p. 37). Hung (2012) recognized the lack of research about the washback effects of classroom-based assessment on learning (p. 33). Previous research has also focused on the use of group work, and research is also needed that examines students' attitudes toward alternative assessments when they are not provided the support of group work. This study focused on the washback effects on ESL learners who participate in individual alternative assessments. 


\section{Research Purpose and Questions}

The purpose of this research was to determine learner attitudes toward an alternative assessment, additional washback effects, and possible relationships between cultures of learning and learner attitudes:

1. What are participants' attitudes before participating in an alternative assessment?

2. Is there a change in participants' attitudes after they complete the assessment? If so, what kind?

3. What are the positive and/or negative washback effects of the alternative assessment on the learners?

4. Is there a relationship between the participants' attitudes toward the poster project and their cultures of learning? 


\section{Methodology}

This study employed mixed methods in order to thoroughly triangulate the data and address a question at different levels. A small number of participants also justified using mixed methods. Pre- and post-tests, provided both quantitative and qualitative data, and other qualitative measures were included. This section describes the context of study, the participants, as well as the materials and instruments used for the study.

\section{Context of Study}

The present study was conducted in an Intensive English Program (IEP) at a large university in the Pacific Northwest, which, based on my observations of several classes, serves students from several countries around the world such as Saudi Arabia, China, Kuwait, Iraq, Japan, South Korea, and more. For many students, the IEP program is a stepping stone to their mainstream university coursework. It not only prepares students linguistically but also culturally and pragmatically. In essence, students in the IEP program learn how to go to college in the United States. Consequently, the assignments, assessments and expectations in their IEP should represent what students will find in their mainstream coursework.

One of the instructors in this program, who is particularly interested in various forms of assessment, has implemented one kind of alternative assessment regularly into her Advanced Academic Reading class (AAR): a poster project illustrating the application of themes from a book. Because of this assessment, the present study was conducted in the AAR class, which is the highest level in this program and often the last class students take before beginning their mainstream coursework. This instructor is an 
American female with a Master's degree in TESOL and has taught in a university-based IEP for seven years. She has taught the AAR course more than 10 times, however, this was the fifth time she administered the poster project in the AAR class. Data collection took place during summer session. The eight-week summer course began the last full week of June and ended the second week of August. Data was collected from two sections of the same course. Each section met twice per week for approximately two hours each class meeting. One section met in the morning and the other in the afternoon.

\section{Participants}

I found a convenience sample and a culturally heterogeneous population in this English for Academic Purposes (EAP) class. A mix of 26 male and female students represented learning cultures from Saudi Arabia, Kuwait, China, Taiwan, Brazil, and Libya. Students' first language (L1) backgrounds included Arabic, Mandarin, and Portuguese. Table 1, below, shows the percentage of participants from each country. For this study, China and Taiwan are combined as one culture of learning called, Chinesespeaking Countries. Because the educational styles and values in Taiwan and China are very similar, it is more representative of the culture of learning to combine the two countries rather than eliminate all responses from the only Taiwanese participant. I consulted with a Taiwanese colleague before making this decision, and my decision was approved based on the fact that my focus is on education and not politics or nationalism. The proficiency levels of the participants, although all of them were in the highest level class within the IEP program, varied. New students may test into a class level while other students advance to the next level based on their grades. According to the 
instructor, at the time this study was conducted, students were less proficient than the typical student in her AAR class. It is possible that the lax nature of summer term accounted for the discrepancy.

Of the 26 AAR students who agreed to participate in this study, two were eliminated from the data. I did not have a complete data set from one, and the other was eliminated because comparison of the reverse-coded items proved the responses of the latter participant to be inconsistent. Thus, the data for that participant were eliminated leaving a total of 24 participants. The following information regarding the participants will only include information from the final 24 . The enrollment of the 24 participants was equally divided: 12 were enrolled as pass/no pass, and 12 were enrolled for a grade.

Table 1

Number of Participants by Culture of Learning and Enrollment

\begin{tabular}{|c|c|c|c|}
\hline & A-F Grade & Pass/ No Pass & Total \\
\hline Saudi Arabia & 2 & 6 & $\mathbf{8}$ \\
\hline $\begin{array}{c}\text { Chinese-Speaking } \\
\text { Countries }\end{array}$ & 3 & 2 & $\mathbf{5}$ \\
\hline Libya & 1 & 3 & $\mathbf{4}$ \\
\hline Brazil & 4 & 0 & $\mathbf{3}$ \\
\hline Kuwait & 2 & 1 & $\mathbf{2 4}$ \\
\hline Total & $\mathbf{1 2}$ & $\mathbf{1 2}$ & \\
\hline
\end{tabular}


As Tables 2, 3, 4, and 5 below demonstrate, participants had varied previous experience with alternative assessments at the time of this study. On the pretest, participants from Chinese-speaking countries reported having comparable experiences with alternative assessments in their home countries and in the US. However, participants from Brazil and Kuwait reported having more experience with alternative assessments in their home countries than they had in the US, whereas participants from Saudi Arabia and Libya experienced more alternative assessments in the US than in their respective home countries. 
Table 2

Participants' Previous Experience with Alternative Assessments in Their Home Countries

\begin{tabular}{|c|c|c|c|c|c|c|}
\hline \multicolumn{7}{|c|}{ Previous Experience in Home Country } \\
\hline & $\begin{array}{c}\text { Saudi } \\
\text { Arabia }\end{array}$ & $\begin{array}{c}\text { Chinese- } \\
\text { Speaking }\end{array}$ & Libya & Brazil & Kuwait & Total \\
\hline $\begin{array}{c}\text { Received a } \\
\text { Grade for } \\
\text { Making a } \\
\text { Poster }\end{array}$ & 3 & 1 & 1 & 4 & 2 & 11 \\
\hline $\begin{array}{c}\text { Received a } \\
\text { Grade for } \\
\text { Giving a } \\
\text { Presentation }\end{array}$ & 3 & 5 & 1 & 4 & 2 & 15 \\
\hline $\begin{array}{c}\text { Designed a } \\
\text { Poster } \\
\text { Independently }\end{array}$ & 2 & 2 & 3 & 3 & 2 & 12 \\
\hline $\begin{array}{c}\text { Given a } \\
\text { Presentation } \\
\text { Independently }\end{array}$ & 3 & 5 & 1 & 4 & 2 & $\mathbf{1 5}$ \\
\hline
\end{tabular}


Table 3

Participants' Previous Experience with Alternative Assessments in the United States

\begin{tabular}{|c|c|c|c|c|c|c|}
\hline \multicolumn{7}{|c|}{ Previous Experience in the United States } \\
\hline & $\begin{array}{c}\text { Saudi } \\
\text { Arabia }\end{array}$ & $\begin{array}{c}\text { Chinese- } \\
\text { Speaking }\end{array}$ & Libya & Brazil & Kuwait & Total \\
\hline $\begin{array}{c}\text { Received a } \\
\text { Grade for } \\
\text { Making a } \\
\text { Poster }\end{array}$ & 5 & 2 & 1 & 0 & 0 & $\mathbf{8}$ \\
\hline $\begin{array}{c}\text { Received a } \\
\text { Grade for } \\
\text { Giving a } \\
\text { Presentation }\end{array}$ & 8 & 5 & 4 & 2 & 3 & $\mathbf{2 2}$ \\
\hline $\begin{array}{c}\text { Designed a } \\
\text { Poster } \\
\text { Independently }\end{array}$ & 5 & 2 & 1 & 0 & 0 & $\mathbf{8}$ \\
\hline $\begin{array}{c}\text { Given a } \\
\text { Presentation } \\
\text { Independently }\end{array}$ & 7 & 5 & 4 & 2 & 3 & $\mathbf{2 1}$ \\
\hline
\end{tabular}


Table 4

Frequency of Participants' Previous Experience with Alternative Assessments at Home

Frequency of Previous Experience with Alternative Assessments in Home Country

\begin{tabular}{|c|c|c|c|c|c|c|}
\hline & $\begin{array}{c}\text { Saudi } \\
\text { Arabia }\end{array}$ & $\begin{array}{c}\text { Chinese- } \\
\text { Speaking }\end{array}$ & Libya & Brazil & Kuwait & Total \\
\hline $\begin{array}{c}\text { Home } \\
\text { Country: } \\
\text { Very Often }\end{array}$ & 0 & 1 & 0 & 1 & 0 & $\mathbf{2}$ \\
\hline $\begin{array}{c}\text { Home } \\
\text { Country: } \\
\text { Sometimes }\end{array}$ & 3 & 3 & 1 & 2 & 1 & $\mathbf{1 0}$ \\
\hline $\begin{array}{c}\text { Home } \\
\text { Country: } \\
\text { Rarely }\end{array}$ & 3 & 1 & 3 & 1 & 2 & $\mathbf{1 0}$ \\
\hline $\begin{array}{c}\text { Home } \\
\text { Country: } \\
\text { Never }\end{array}$ & 2 & 0 & 0 & 0 & 0 & $\mathbf{2}$ \\
\hline
\end{tabular}


Table 5

Frequency of Participants' Previous Experience with Alternative Assessments in the US

Frequency of Previous Experience with Alternative Assessments in the US

\begin{tabular}{|c|c|c|c|c|c|c|}
\hline & $\begin{array}{c}\text { Saudi } \\
\text { Arabia }\end{array}$ & $\begin{array}{c}\text { Chinese- } \\
\text { Speaking }\end{array}$ & Libya & Brazil & Kuwait & Total \\
\hline $\begin{array}{c}\text { United } \\
\text { States: } \\
\text { Very Often }\end{array}$ & 0 & 1 & 1 & 1 & 0 & $\mathbf{3}$ \\
\hline $\begin{array}{c}\text { United } \\
\text { States: } \\
\text { Sometimes }\end{array}$ & 8 & 3 & 2 & 0 & 1 & $\mathbf{1 4}$ \\
\hline $\begin{array}{c}\text { United } \\
\text { States: } \\
\text { Rarely }\end{array}$ & 0 & 1 & 1 & 2 & 2 & $\mathbf{6}$ \\
\hline $\begin{array}{c}\text { United } \\
\text { States: } \\
\text { Never }\end{array}$ & 0 & 0 & 0 & 1 & 0 & $\mathbf{1}$ \\
\hline
\end{tabular}

\section{Materials}

The alternative assessment administered to the students in their classroom was the only material used in this study. The assessment description, specifications, instructions, as well as the rubric were all developed by the instructor of the class (see Appendix D), who had administered the same assessment in previous classes. In the AAR course, students were expected to read the book, Travel as a Political Act by Rick Steves, and develop skills from Bloom's Taxonomy such as analysis, evaluation, and synthesis. As a summative assessment, the students individually prepared and presented a poster which 
introduced a place to an audience and how they could travel politically there based on principles and ideas from Steves's book. According to the rubric, as shown in Table 6 below, students' grades were determined by five dimensions: content focus, sources of information, visual presentation, oral presentation, and creativity and level of originality. 
Table 6

Rubric for AAR Poster Project

\begin{tabular}{|c|c|c|c|}
\hline & $\mathbf{C}$ & B & $\mathbf{A}$ \\
\hline $\begin{array}{l}\text { Content } \\
\text { focus }\end{array}$ & $\begin{array}{l}\text { The topic of the } \\
\text { poster corresponds } \\
\text { to a topic from the } \\
\text { text but is very } \\
\text { general. }\end{array}$ & $\begin{array}{l}\text { The topic of the } \\
\text { poster corresponds to } \\
\text { a topic/theme from } \\
\text { the book and has } \\
\text { been narrowed or } \\
\text { focused. }\end{array}$ & $\begin{array}{l}\text { The topic of the poster } \\
\text { corresponds to a } \\
\text { topic/theme from the book, } \\
\text { is well-narrowed, and } \\
\text { demonstrates clear } \\
\text { analysis. }\end{array}$ \\
\hline $\begin{array}{l}\text { Sources of } \\
\text { information }\end{array}$ & $\begin{array}{l}\text { The information } \\
\text { provided comes } \\
\text { from one source } \\
\text { (book, article, } \\
\text { interview, own } \\
\text { experience) }\end{array}$ & $\begin{array}{l}\text { The information } \\
\text { provided comes from } \\
2 \text { sources. }\end{array}$ & $\begin{array}{l}\text { The information provided } \\
\text { comes from more than } 2 \\
\text { sources. }\end{array}$ \\
\hline $\begin{array}{l}\text { Visual } \\
\text { presentation }\end{array}$ & $\begin{array}{l}\text { The organization of } \\
\text { the information on } \\
\text { the poster is messy } \\
\text { or very simple. }\end{array}$ & $\begin{array}{l}\text { The organization and } \\
\text { presentation of the } \\
\text { materials on the } \\
\text { poster is easy to } \\
\text { follow and clean. }\end{array}$ & $\begin{array}{l}\text { The presentation and } \\
\text { organization of materials } \\
\text { on the poster enhances the } \\
\text { analysis of concepts and is } \\
\text { professional. }\end{array}$ \\
\hline $\begin{array}{l}\text { Oral } \\
\text { presentation }\end{array}$ & $\begin{array}{l}\text { The oral } \\
\text { presentation consists } \\
\text { mainly of reading } \\
\text { information on the } \\
\text { poster. }\end{array}$ & $\begin{array}{l}\text { The oral presentation } \\
\text { adds some } \\
\text { information to the } \\
\text { poster. }\end{array}$ & $\begin{array}{l}\text { The oral presentation } \\
\text { significantly enhanced the } \\
\text { analysis presented on the } \\
\text { poster. }\end{array}$ \\
\hline $\begin{array}{l}\text { Creativity } \\
\text { and level of } \\
\text { originality }\end{array}$ & $\begin{array}{l}\text { The poster illustrates } \\
\text { an idea or theme } \\
\text { from the text. } \\
\text { Only one medium is } \\
\text { used to illustrate the } \\
\text { theme. } \\
\text { The information had } \\
\text { been discussed } \\
\text { previously. }\end{array}$ & $\begin{array}{l}\text { The poster } \\
\text { demonstrates a new } \\
\text { way of } \\
\text { thinking/viewpoint } \\
\text { on a topic. } \\
\text { More than one } \\
\text { medium is used. }\end{array}$ & $\begin{array}{l}\text { The poster demonstrates } \\
\text { original thought, creativity, } \\
\text { and a deeper level of } \\
\text { analysis and synthesis than } \\
\text { previously discussed in } \\
\text { class or in earlier } \\
\text { assignments. } \\
\text { More than one medium is } \\
\text { used. }\end{array}$ \\
\hline
\end{tabular}


Because of this breakdown, the components of the poster accounted for a greater portion of the grade than the student's presentation of it on the last day of class. The grade for the poster project was 10 percent of the students' final course grade.

\section{Instruments}

Pre- and post-tests (see Appendices A and B) were administered inquiring after students' experience with alternative assessments as well as their feelings and preferences regarding assessment types. After the participants were informed of the assignment in class, complete with instructions and a rubric, they were administered the pre-test. The pre-test included 10 closed questions to determine what kind, if any, and how much previous experience the participants had had making a poster or giving a presentation for a grade. In addition, 26 Likert-scale items were designed to gain information about participants' assessment preferences, attitudes toward assessments, and their perceptions of their own learning from the assessment in question. These 26 items ask 13 questions twice, once framed negatively and again framed positively to allow for reverse-coding. A similarly designed post-test was administered after participants completed the assignment, approximately two weeks after the pre-test was administered. The post-test included all of the pre-test items minus the initial background questions hoping to elicit any changes that may have occurred in the students' attitudes as well as whether they believed they learned something from completing the assessment. Tables 7 and 8 below show the questions from the pre- and post-tests, arranged in their reverse-coded pairs and organized by question domain. The four question domains for the Likert-scale questions included attitudes, experience, innovativeness, and learning. The questions were 
developed first and later organized by their themes into domains in preparation for data analysis. The post-test has 27 Likert-scale items instead of 26. The extra item is highlighted in Table 8 below. Five open-ended questions at the end of both the pre- and post-tests were intended to elicit information which would add depth and understanding to some of the closed questions. 
Table 7

Breakdown of the Likert-Scale Items on the Pre-test

\begin{tabular}{|c|c|c|}
\hline Domain & Questions & Reverse-Coded Questions \\
\hline \multirow[t]{8}{*}{ Attitudes } & $\begin{array}{l}\text { I am excited about designing a } \\
\text { poster to illustrate a theme from } \\
\text { the book I read. }\end{array}$ & $\begin{array}{c}\text { I don't like that I have to design a poster } \\
\text { to illustrate a theme from the book I } \\
\text { read. }\end{array}$ \\
\hline & $\begin{array}{c}\text { Tests are not necessarily the best } \\
\text { way to see whether someone has } \\
\text { learned information. }\end{array}$ & $\begin{array}{l}\text { Taking a test is the only way to really } \\
\text { know if someone has learned something. }\end{array}$ \\
\hline & $\begin{array}{c}\text { I feel comfortable with designing a } \\
\text { poster as a way to present } \\
\text { information } \\
\end{array}$ & $\begin{array}{l}\text { I don't feel comfortable presenting } \\
\text { information by designing a poster. }\end{array}$ \\
\hline & $\begin{array}{l}\text { I feel I learn better when I have the } \\
\text { chance to use my creative skills. }\end{array}$ & $\begin{array}{c}\text { I do not learn as well when I do creative } \\
\text { tasks. }\end{array}$ \\
\hline & $\begin{array}{c}\text { I feel confident about my ability to } \\
\text { design a poster. }\end{array}$ & $\begin{array}{c}\text { I feel anxious or nervous when I have to } \\
\text { design a poster. }\end{array}$ \\
\hline & $\begin{array}{c}\text { This assignment is useful because I } \\
\text { will need to design posters in the } \\
\text { future. }\end{array}$ & $\begin{array}{c}\text { This assignment is not useful to me } \\
\text { because I do not expect to design posters } \\
\text { in the future. }\end{array}$ \\
\hline & $\begin{array}{c}\text { If I had the choice between taking } \\
\text { a test and making a poster, I would } \\
\text { choose to make a poster. }\end{array}$ & $\begin{array}{l}\text { I wish I could take a test about the book } \\
\text { instead of prepare a poster. }\end{array}$ \\
\hline & $\begin{array}{l}\text { The instructions for the project } \\
\text { were very clear to me. I know } \\
\text { what I am supposed to do. }\end{array}$ & $\begin{array}{l}\text { To be honest, I don't really know what I } \\
\text { am supposed to do for this assignment. }\end{array}$ \\
\hline \multirow[t]{2}{*}{ Experience } & $\begin{array}{c}\text { In my home country, I showed my } \\
\text { learning by doing something } \\
\text { different from taking a test at least } \\
\text { one time. }\end{array}$ & $\begin{array}{l}\text { In my home country, I always showed } \\
\text { my learning by taking a test. }\end{array}$ \\
\hline & $\begin{array}{c}\text { I used all of the levels of learning } \\
\text { in Bloom's Taxonomy to show my } \\
\text { learning in different classes } \\
\text { (science, math, language, etc.) in } \\
\text { my home country. }\end{array}$ & $\begin{array}{l}\text { My educational experience in my home } \\
\text { country did not include all of the levels } \\
\text { of learning from Bloom's Taxonomy. } \\
\text { (Think of all your subjects.) }\end{array}$ \\
\hline $\begin{array}{c}\text { Innovative- } \\
\text { ness }\end{array}$ & $\begin{array}{c}\text { I like to try new ways to study and } \\
\text { learn. }\end{array}$ & $\begin{array}{c}\text { When I try new ways to learn or study, it } \\
\text { is very hard for me to learn. }\end{array}$ \\
\hline
\end{tabular}




\begin{tabular}{|c|c|c|}
\hline Domain & Questions & Reverse-Coded Questions \\
\hline Learning & $\begin{array}{c}\text { Designing a poster will help me to } \\
\text { improve my English language } \\
\text { skills. }\end{array}$ & $\begin{array}{c}\text { Designing a poster is not a good test of } \\
\text { my English language skills. }\end{array}$ \\
\cline { 2 - 3 } & $\begin{array}{c}\text { I think I will learn something by } \\
\text { designing a poster that I would not } \\
\text { learn by taking a test. }\end{array}$ & $\begin{array}{c}\text { I don't think I will learn very much from } \\
\text { designing a poster. }\end{array}$ \\
\hline
\end{tabular}


Table 8

Breakdown of the Likert-Scale Items on the Post-test

\begin{tabular}{|c|c|c|c|}
\hline Domain & \multicolumn{2}{|c|}{ Questions } & Reverse-Coded Questions \\
\hline \multirow[t]{8}{*}{ Attitudes } & \multicolumn{2}{|c|}{$\begin{array}{l}\text { I enjoyed designing a poster to illustrate a } \\
\text { theme from the book I read. }\end{array}$} & $\begin{array}{l}\text { I did not enjoy designing a poster } \\
\text { to illustrate a theme from the book } \\
\text { I read. }\end{array}$ \\
\hline & \multicolumn{2}{|c|}{$\begin{array}{c}\text { Tests are not necessarily the best way to } \\
\text { see whether someone has learned } \\
\text { information. }\end{array}$} & $\begin{array}{l}\text { Taking a test is the only way to } \\
\text { really know if someone has } \\
\text { learned something. }\end{array}$ \\
\hline & \multicolumn{2}{|c|}{$\begin{array}{l}\text { I was comfortable presenting my poster } \\
\text { to my peers. }\end{array}$} & $\begin{array}{l}\text { Presenting my poster to my peers } \\
\text { made me feel uncomfortable. }\end{array}$ \\
\hline & \multicolumn{2}{|c|}{$\begin{array}{l}\text { I feel I learn better when I have the } \\
\text { chance to use my creative skills. }\end{array}$} & $\begin{array}{l}\text { I do not learn as well when I do } \\
\text { creative tasks. }\end{array}$ \\
\hline & \multicolumn{2}{|c|}{$\begin{array}{l}\text { I am confident about how I designed my } \\
\text { poster. }\end{array}$} & $\begin{array}{c}\text { I think my poster could have been } \\
\text { designed more effectively. }\end{array}$ \\
\hline & $\begin{array}{l}\text { Designing the poster } \\
\text { was more useful to } \\
\text { me than I thought it } \\
\text { would be. }\end{array}$ & \begin{tabular}{|c|} 
Designing the \\
poster was less \\
useful to me than I \\
thought it would \\
be.
\end{tabular} & $\begin{array}{l}\text { Designing the poster was just as } \\
\text { useful to me as I expected it } \\
\text { would be. }\end{array}$ \\
\hline & \multicolumn{2}{|c|}{$\begin{array}{l}\text { If I had the choice between taking a test } \\
\text { and making a poster, I would have } \\
\text { chosen to make a poster. }\end{array}$} & $\begin{array}{l}\text { I wish I could have taken a test } \\
\text { about the book instead of } \\
\text { preparing a poster. }\end{array}$ \\
\hline & \multicolumn{2}{|c|}{$\begin{array}{l}\text { The instructions for this project were } \\
\text { very clear to me. I understood what I } \\
\text { was supposed to do. }\end{array}$} & $\begin{array}{l}\text { To be honest, I did not understand } \\
\text { what I was supposed to do for this } \\
\text { project. }\end{array}$ \\
\hline \multirow[t]{2}{*}{ Experience } & \multicolumn{2}{|c|}{$\begin{array}{l}\text { In my home country, I showed my } \\
\text { learning by doing something different } \\
\text { than taking a test at least once. }\end{array}$} & $\begin{array}{c}\text { In my home country, I always } \\
\text { showed my learning by taking a } \\
\text { test. }\end{array}$ \\
\hline & \multicolumn{2}{|c|}{$\begin{array}{l}\text { I used all of the levels of learning in } \\
\text { Bloom's Taxonomy to show my learning } \\
\text { in different classes (science, math, } \\
\text { language, etc.) in my home country. }\end{array}$} & $\begin{array}{c}\text { My educational experience in my } \\
\text { home country did not include all } \\
\text { of the levels of learning from } \\
\text { Bloom's Taxonomy. } \\
\text { (Think of all your subjects.) }\end{array}$ \\
\hline $\begin{array}{l}\text { Innovative- } \\
\text { ness }\end{array}$ & \multicolumn{2}{|c|}{ I like to try new ways to study and learn. } & $\begin{array}{c}\text { When I try new ways to learn or } \\
\text { study, it is very hard for me to } \\
\text { learn. }\end{array}$ \\
\hline
\end{tabular}




\begin{tabular}{|c|c|c|}
\hline Domain & Questions & Reverse-Coded Questions \\
\hline Learning & $\begin{array}{c}\text { Designing the poster allowed me to show } \\
\text { my English language ability. }\end{array}$ & $\begin{array}{c}\text { Designing the poster did not allow } \\
\text { me to show my real English } \\
\text { language ability. }\end{array}$ \\
\cline { 2 - 3 } & $\begin{array}{c}\text { I learned something by designing the } \\
\text { poster that I would not have learned by } \\
\text { studying for a test. }\end{array}$ & $\begin{array}{c}\text { I would have learned more in this } \\
\text { reading class if I had studied for a } \\
\text { test about the book. }\end{array}$ \\
\hline
\end{tabular}

\section{Data Collection Procedures}

Pre- and post-test. Participants were administered the pre-test after they learned about the poster project. I administered the post-test to participants prior to their final exam, which occurred during the class meeting after the presentations were made. Each paper questionnaire took 20-30 minutes to complete and both were completed in the classroom during class time. Participants identified themselves using a personally selected pseudonym so that their pre- and post-tests could be matched. The instructor of the course kept a roster of the participants' names and pseudonyms, which proved useful as many participants had forgotten their pseudonyms by the time the post-test was administered. I did not have access to the roster.

Observations and interview. In order to add depth to the research and triangulate the data, I observed some of the classes. I attended several classes between the first and last day of the course, including the day the participants were first introduced to the assignment and the day of the presentations. Seated sideways against a wall near the front of the classroom gave me an accessible view of the whole class, including the instructor, the board, and students' faces. I kept hand-written notes of what I saw and heard from the instructor and the students. Students' behaviors, questions, and facial 
expressions were of particular interest to me. Such behavioral cues, I believed, would provide more insight into the attitudes of the participants as they learned about the assignment.

Alderson and Hamp-Lyons (1996) "saw the observation of actual TOEFL preparation classes as the most important component of [their] data" (p. 287). Lambert (2008) also made use of observations by video-recording the presentations because he was also grading them. As an observer and not an instructor of the course, I was free from the distraction of evaluating student presentations and able to observe interactions between students, their behaviors during their own presentations, and their reactions after the class was finished.

After the poster presentations, I also interviewed the instructor about her views and impressions regarding this particular term of poster presentations. For the interview, I asked the instructor a series of pre-determined questions (see Appendix C) regarding her previous experience administering the assignment, her expectations for the participants, as well as the background of her implementation of the assignment in the AAR course. I did not interview any student participants. 


\section{Data Analysis}

\section{Quantitative Data}

As a mixed methods study, multiple methods were used in the collection and analysis of the data. Quantitative data were analyzed using the statistics software program, Statistical Package for Social Sciences (SPSS) Version 23.0. Participants' answers were entered for each question. It should be noted that because of the reverse coding in the questions asked, answers to reverse-coded questions were flipped in order that all answers reflected the same information. For example, given a pair of questions, if a student answered strongly agree to the positively framed question and strongly disagree to its counterpart, I assigned the same score for both questions because the participant expressed the same attitude. As previously mentioned, the Likert-scale questions were categorized into four question domains: attitudes, experience, innovativeness, and learning. Each participant was given an average score per question domain for the pretest as well as the post-test. The score was the mean of all the responses within that question domain. The participants' attitude gain was calculated by subtracting the mean pre-test scores from the mean post-test scores.

Because descriptive statistics revealed the data was normally distributed, paired ttests were used to test for statistical significance between the attitudes' score for the preand post-tests. SPSS was also used to run CrossTabs to view any possible correlations between participants' cultures of learning and their gain scores for each question domain. 


\section{Qualitative Data}

Three kinds of qualitative data were collected to triangulate the quantitative data: participants' written answers to open-ended questions, a follow-up interview with the instructor, and my own classroom observations. There were five open-ended questions included in the last part of both the pre- and post-tests, which were administered to participants on two separate occasions, once on the day they learned about the poster project and again after the poster projects were complete. Participants' verbatim responses were informative for the results. For example, if the quantitative data revealed a participant had an average positive attitude toward the poster project, that participant's open-ended responses provided a description of his or her attitude. Careful examination of such responses revealed insights pertinent to the research questions, which were included in the results and discussion sections. Hatch (2002) recommends developing "a set of categories of meaning or domains that reflects relationships represented in the data" (p. 164). "Discovering domains gives researchers a way of getting at how participants organize their understandings and operate in their worlds" (Hatch, 2002, p. 165). With specific categories, or domains, in mind, such as what students learned or their expressed attitudes toward the poster, the data were analyzed for evidence of support and opposition of those categories. Further analysis of all the qualitative data, including observations, the interview with the instructor, and participants' open-ended responses was conducted by "searching for patterns that repeat in the data and for patterns that show linkages among different parts of data" (Hatch, 2002, p. 173). Notes 
from the interview with the interviewer were surveyed for insights regarding the poster project as well as the instructor's previous experience administering the poster project. 


\section{Results}

The following narrative is taken from my notes during my observations of the classes. The narrative invites the reader into the context in which the pre- and post-tests were administered as well as provides a preliminary glimpse of the students' attitudes as demonstrated by their behavior. My notes begin with the distribution of the final project assignment, which occurred 12 days prior to the project presentations. Direct quotes are recorded verbatim and italicized; grammatical errors were not corrected. The observations were analyzed by identifying patterns and seeing "what connections can be found among them" (Hatch, 2002, p. 173).

Six weeks into the eight week summer course, just before the ten minute break mid-class, the instructor passes out the final assignment, (see Appendix D), which includes the scope of the project, her expectations, and her rubric for the project. The students do not read it, nor do they even look at it. They use their break to check their phones, talk, and stretch their legs. After 10 minutes, the class reconvenes and the instructor begins to explain the summative assignment for the course. She discusses strategies for how to end this term well and describes the task as a heavy assignment. At this point, students are looking over the handout. I notice a student sigh as her mouth forms the word, poster. Students are given a few minutes to read over the assignment with a partner. I hear students anticipate the end of the summer term with phrases like, then we will be free and I can't wait! In reference to Bloom's taxonomy, which is taught explicitly in AAR, the instructor asks, what kind of critical thinking is needed for this poster? Students respond, create and apply. Students begin asking clarification 
questions: I should take a quote from that chapter? We can choose a specific point? The instructor affirms both questions saying she wants them to focus on a topic. The instructor goes over the rubric, the same one she will use to grade their assignments, and students begin to ask the instructor questions about the apparent two-fold nature of the project: a poster and a presentation. How long we should prepare a speech? The instructor provides a frame of reference: It's like a conference. I see a student look at her classmate with eyes wide and say, wow. The instructor advises the students that the poster should speak for itself.

As five minutes of clarification questions come to a close, the teacher asks, how many of you have made a poster before? Only a few students raise their hand. One student qualifies his hand raised by saying, at home. Some questions are more logistical. Two students look together at a cell phone and show its display to the instructor. The students are searching for posters to purchase online. They look at options that cost ten dollars and more. The instructor advises a much lower dollar amount as a maximum price for a poster and recommends stores for purchasing posters as well as how to travel there. Another student inquiries about doing a PowerPoint in lieu of a poster, but the answer is no.

The following class meeting, the first in week seven of this term, marks the first time the instructor implements an additional task to help students prepare for their poster projects. At this point, students have had time to think about the poster project and their topic. Based on the first week's diagnostic test, the instructor anticipates this class needing more help than previous terms. Adapting a task she's used for other 
assignments, she uses the 10 minute break to line the walls at the back of the classroom with posters made by students from previous classes. By contrast to the previous day of class, students begin to explore the posters before the break is over. When the instructor calls the class back together, she advises the students to carry their rubrics with them as they observe each poster so that they can score them based on how the posters meet the requirements itemized in the rubric. As students embark on their discovery task, the instructor adds, no poster is perfect. I hear students reminding one another of what the instructor said the day before: The poster should speak for itself. Seeing real posters inspires more questions about formatting, including font size, poster size, number of pictures, and amount of text. Maybe I will use quotes from the book, one students says. I hear two students dialoguing about their particular poster ideas and giving one another advice. A couple of students recognize the work of their friends commenting with recognition, Oh, I know her! Eventually, a crowd of inquiries about a particular poster's score calls the instructor to join the poster observations. Your presentation should enhance my understanding of the poster, she tells them. Viewing example posters prompts a teachable moment regarding crediting sources. The instructor takes time to talk about the importance of crediting sources, which is one of her goals for the activity. Viewing actual posters from previous classes seems to make the poster project a reality for some students. One student even asks the instructor during this time, I have to make a poster?

In an interview with her later, the instructor told me one student came to her privately and asked, how long should it take to do the assignment? And another asked her 
to explain the poster presentation one on one. The instructor said, they seem concerned about whether their ideas meet expectations. The active ones ask. She also noticed that those who asked for confirmation of how their work was meeting expectations produced the best posters.

One week later, on the last day of class, students give their presentations. Although the presentations are delivered in the same classroom as their usual class times, the desks are pushed to the side, out of the way, as they might be at a conference. I'm surprised to notice some students are either very late or absent on presentation day. As students arrive, they look at one another's posters. Posters vary in their size and materials. Some posters are large tri-folds with colorful pictures and others are smaller, flat posters with more text. Some students chose to handwrite their information while others typed it. One particularly impressive poster was designed entirely on the computer and printed out poster size.

As students come in, the instructor hands out to every student a piece of colored paper: blue, yellow, purple, or green. The color of paper you're holding determines when you will present, she says. The instructor delivers instructions for the presentation reminding students that when they are not presenting, they should be viewing and listening to their peers' poster presentations. Students are also encouraged to participate by asking questions of their peers. As the students holding blue pieces of paper begin their presentations, students with green, yellow, and purple divide themselves into groups so that every blue student has an audience, even if the instructor is not a part of that audience yet. Each student presents his or her poster approximately four or five times as 
their peers rotate around the room to hear about and see each poster, and the instructor is in their audience only once.

As I walk around the room, I notice several students, if not most, are presenting information about their own countries. Some are presenting about countries they have visited, though they are not from there. Either way, several students are sharing information that is personal to them. They show pictures of landmarks and cultural points of interest with smiles that seem proud and somewhat homesick. A couple of students, who have chosen a local topic of interest, stand out. They are applying themes from the book to a culture already foreign to them, yet presenting the information like experts. Only a few other students have chosen topics set in a culture foreign to themselves. As I make my rounds, students seem to speak with less hesitation and more confidence as they repeatedly present their posters and answer questions to new audiences. When in the audience, students timidly ask questions about their peers' home countries, topic, and posters.

The instructor was generally unimpressed with the quality of most of the posters. The implementation of the discovery activity involving previous posters had the potential to set a standard for the students this summer. However, when I asked the instructor whether she saw an increase in the quality of the posters compared with previous terms, she replied, [I] did not see that happen this term. Still, other posters were very good creating a spectrum of quality of work. The instructor described the poster project as complex and abstract. The assignment was complex in that it involved several pieces, such as research, poster design, and a short presentation. The topics and ideas the 
students chose to focus on were abstract, and thus, more challenging to discuss.

Although very few of her students were able to hit the mark of the poster project, as the instructor told me, one student stood out because she chose to use the same topic of her poster project for a research paper in another class. According to the instructor, the poster project was a vehicle for really deep language learning for this student because the student was able to express his or her ideas graphically, orally, as well as on paper, which promoted mastery of application.

Interpretation. The instructor's use of positive phrases and reassurances when introducing the assessment, from the overarching how to end the term well to the practical recommendation of the use of inexpensive posters, set a positive tone for the start of the poster project. However, students' reactions like the wide-eyed, wow and the few hands raised as evidence of previous experience, revealed their uncertainties about the poster project. Their questions included those of logistics, content, and grading. Having the students gain familiarity with the rubric, and thus expectations, by scoring previously made posters provided support for students in more than one way. First, all the students read the rubric. Second, students saw posters made by students like themselves giving the poster project a sense of achievability. Students also got to see real examples, which may have set a visual standard in their minds of what was expected and what had been done. The planning and advising that happened between students may have fostered community and peer support. While some students were creating pictures in their head of what their instructor expected as well as preliminary designs of their own posters, others were just realizing the scope of the assignment, as shown by the question 
asked during the activity: I have to make a poster? This shows that students were working at different paces from different positions of readiness regarding the poster project. Some claimed previous experience making posters, though most did not. Some saw an example and began planning their own design, while others saw examples and realized the task before them for the first time, even though the assignment had been thoroughly discussed the previous class meeting.

Although students did not seem excited about doing a poster project in their class, several saw the poster project as an opportunity to make something that was personally meaningful, even something that could foster community building and cultural exchange. Some students displayed personal photos of places visited and showed cultural artifacts from their home countries. These students appeared confident in their topic, as they should because typically people are experts about their home countries. As audience members, students still appreciated the cultural exchange by asking questions framed by “in your country" and nodding while the presenter answered. The students' efforts to ask questions of their peers demonstrated interest and support, likely resulting in an improved sense of community within the classroom.

It is clear that the instructor believes in the value of the poster project because she not only continues to assign it, but she continues to improve it; the addition of the rubric scoring activity with previous posters serves as an example. She sees the value of practicing different levels of learning, like understanding, applying, and creating. Knowing students will likely encounter different kinds of alternative assessments in the future, she feels a responsibility to facilitate practice with them. Finally, she sees the 
possibility of students, who want to, to experience deeper learning as they investigate their topic, apply information from their assigned text, and present it graphically. Setting the stage like a conference casts the students as experts on their project, which could possibly facilitate greater learner autonomy.

These observations provided the first indications that participants' attitudes toward the poster project varied. They also inspired the early development of categories designed to organize the data in order to reveal patterns as well as make connections between the patterns. The following section presents the results of each of the four research questions in depth with both quantitative and qualitative findings. Results regarding the fourth research question, which asks, is there a relationship between the participants' attitudes toward the poster project and their cultures of learning? are presented as they pertain to each of the other research questions. All of the findings are discussed in the following Discussion section. Direct quotes from participants' responses to open-ended questions on the questionnaires are primary results, and they are quoted verbatim. Spelling and parts of speech were corrected only if such modifications would allow for easier reading, and these are indicated in brackets. Mistakes that did not seem to impair reading were left uncorrected to preserve the authenticity of the participants' quotes. The participant's culture of learning as well as whether the response is from the pre- or post-test are indicated parenthetically at the end of the quote, (Culture, Test), and items from the questionnaires are italicized. 


\section{Research Question \#1: What are participants' attitudes before participating in an alternative assessment?}

Of the quantitative data, only the participants' pre-test mean attitudes scores were used to address this research question. Each participant's responses to the Likert-scale questions within the 'attitude' question domain were averaged to yield a mean attitude score. An attitude score was calculated for the pre- and post-tests respectively, however, only the attitude scores for the pre-tests were used to address this question. The qualitative data that informed this question included responses to the open-ended questions on the pre-test, particularly the third question, Describe how you feel about doing this assignment. Would you rather take a test? Why or why not? All of the items related to the 'attitude' domain are set apart in Table 9 below. 
Table 9

Items from the Attitude Domain on the Pre-Test

\section{Items from the Attitude Domain on the Pre-Test}

Likert- I am excited about designing a poster to illustrate a theme from the book I read. Scale

I don't like that I have to design a poster to illustrate a theme from the book I read.

Tests are not necessarily the best way to see whether someone has learned information.

Taking a test is the only way to really know if someone has learned something.

I feel comfortable with designing a poster as a way to present information

I don't feel comfortable presenting information by designing a poster.

I feel I learn better when I have the chance to use my creative skills.

I do not learn as well when I do creative tasks.

I feel confident about my ability to design a poster.

I feel anxious or nervous when I have to design a poster.

This assignment is useful because I will need to design posters in the future.

This assignment is not useful to me because I do not expect to design posters in the future.

If I had the choice between taking a test and making a poster, I would choose to make a poster.

I wish I could take a test about the book instead of prepare a poster.

The instructions for the project were very clear to me. I know what I am supposed to do.

To be honest, I don't really know what I am supposed to do for this assignment.

Open- Will giving this assignment be useful for your learning? How or how not? Ended

Describe how you feel about doing this assignment. Would you rather take a test? Why or why not? 
Table 10, below, shows the mean attitude scores of the participants from the pretest, which range from 2.00 to 4.79 on a scale of 1 to 5 . This indicates that a range of attitudes were represented including negative, neutral, and positive. However, there was a greater representation of positive attitudes than negative.

The fourth research question asks about a possible relationship between participants' cultures of learning and the findings of each previous research question. In this case, is there a relationship between the participants' cultures of learning and their attitudes toward the poster project prior to doing the assessment? Table 10, below, shows that more participants from Saudi Arabia had a negative mean attitude score on the pretest than from another learning culture. One participant each from Libya and Brazil also had negative mean attitude scores. Five participants had neutral mean attitude scores, and surprisingly, 14 participants, (58\%), had positive mean attitude scores on the pre-test. Although it appears that a participant was more likely to have a negative mean attitude score on the pre-test if he or she was from Saudi Arabia, the number is too small to assert a relationship between the participants' cultures of learning and their mean attitude scores on the pre-test. 
Table 10

Participants' Mean Attitude Scores on the Pre-Test

\begin{tabular}{|c|c|c|c|c|c|c|c|c|c|c|c|c|}
\hline \multicolumn{13}{|c|}{ Pre-Test Mean Attitude } \\
\hline & \multicolumn{5}{|c|}{ Negative } & \multirow{2}{*}{\begin{tabular}{|c|c} 
& Neutral \\
5 & 3
\end{tabular}} & \multicolumn{5}{|c|}{ Positive } & \multirow{2}{*}{\begin{tabular}{|l}
$\begin{array}{l}\text { Overall } \\
\text { Total }\end{array}$ \\
\end{tabular}} \\
\hline $\begin{array}{l}\text { Culture } \\
\text { of } \\
\text { Learning }\end{array}$ & $\begin{array}{c}\text { Total } \\
\text { Negative }\end{array}$ & 1.0 & 1.5 & 2.0 & 2.5 & & 3.5 & 4.0 & 4.5 & 5.0 & $\begin{array}{c}\text { Total } \\
\text { Positive }\end{array}$ & \\
\hline $\begin{array}{l}\text { Saudi } \\
\text { Arabia }\end{array}$ & 3 & 0 & 0 & 1 & 2 & 2 & 3 & 0 & 0 & 0 & 3 & 8 \\
\hline $\begin{array}{l}\text { Chinese- } \\
\text { Speaking }\end{array}$ & $\mathbf{0}$ & 0 & 0 & 0 & 0 & 2 & 1 & 2 & 0 & 0 & 3 & 5 \\
\hline Libya & 1 & 0 & 0 & 0 & 1 & $\mathbf{0}$ & 2 & 1 & 0 & 0 & 3 & 4 \\
\hline Brazil & $\mathbf{0}$ & 0 & 0 & 0 & 0 & 1 & 0 & 2 & 0 & 1 & 3 & 4 \\
\hline Kuwait & 1 & 0 & 0 & 0 & 1 & $\mathbf{0}$ & 1 & 1 & 0 & 0 & 2 & 3 \\
\hline
\end{tabular}

Table 11, below, shows the number of expressed preferences for taking a test or designing a poster as well as expressed attitudes, whether positive, negative, or indifferent, in response to the third open-ended question in the pre-test: Describe how you feel about doing this assignment. Would you rather take a test? Why or why not? 
Table 11

Participants' Responses to the Question: Describe how you feel about doing this assignment. Would you rather take a test? Why or why not?

\begin{tabular}{|c|c|c|c|c|c|c|c|}
\hline & $\begin{array}{c}\text { Culture of } \\
\text { Learning }\end{array}$ & $\begin{array}{c}\text { Saudi } \\
\text { Arabia }\end{array}$ & Chinese & Libya & Brazil & Kuwait & Total \\
\hline $\begin{array}{c}\text { Expressed } \\
\text { Preferences }\end{array}$ & Prefer test & 3 & 0 & 1 & 1 & 1 & $\mathbf{6}$ \\
\cline { 2 - 8 } & $\begin{array}{c}\text { Prefer } \\
\text { poster }\end{array}$ & 2 & 1 & 0 & 0 & 1 & $\mathbf{4}$ \\
\hline $\begin{array}{c}\text { Expressed } \\
\text { Attitudes }\end{array}$ & Positive & 3 & 1 & 2 & 2 & 1 & $\mathbf{9}$ \\
\cline { 2 - 9 } & Negative & 4 & 2 & 2 & 1 & 0 & $\mathbf{9}$ \\
\cline { 2 - 8 } & Indifferent & 0 & 1 & 0 & 0 & 0 & $\mathbf{1}$ \\
\hline
\end{tabular}

Although, in general, not all the participants explicitly stated a preference for taking a test or doing the poster, a $60 \%$ majority of those who did state a preference preferred tests. Based on their own reports, the attitudes of participants prior to beginning work on the assessment were equally split between positive and negative, despite their culture of learning. Due to the consistent pattern of expressed attitudes being split within each culture of learning, it was determined that there was no correlation between participants' expressed attitudes and their cultures of learning. Participants cited different reasons for having positive attitudes. Two of them saw the poster project as something new and different. One participant wrote, "I feel very comfortable doing this assignment because [it] is something different. When you like what you're doing, you learn more" (Brazil, 
Pre-test). Another wrote, 'I'm excited to do it because I didn't do it before and I'm ready to take it as a challenge and new experience and learn something new. I think test and presentation are different than each other" (Kuwait, Pre-test). Time seemed to be an important factor to some participants. Two participants noted the advantage of the poster providing more time than a test would. For example, "I feel confident and I'd rather to this assignment than a test. Because English is not my first language then I like to have more time to write and to review the assignments" (Brazil, Pre-test). Another participant seemed to prefer the poster project only by comparison with a test: "I feel this assignment is better than taking a test because taking a test will give us stressure and feel boring" (Chinese-speaking, Pre-test). The coined word, stressure, could be a blending of stress and pressure, both of which can seriously impact one's attitude.

Although many of the responses were positive like these, other participants described less positive feelings about the assignment. One commented, "Posters are built on creating and tests are built in understand and remember. I prefer understanding than creating" (Saudi Arabia, Pre-test). This quote was interesting because the participant uses terminology from Bloom's Taxonomy, such as understand, remember, and creating, which is explicitly taught in the AAR course. Another participant also described how he felt in terms of learning: "I would rather a test because I don't think that make a poster can help me learn more" (Kuwait, Pre-test). This participant seemed to value assessments for how much they will help him or her learn. Finally, two participants expressed concern for the speaking aspect of presenting a poster, which brings into question the validity of the reading assessment. One reported, "Yes, test is more fair than 
project. The one who speaks good they take good grade" (Saudi Arabia, Pre-test), rationalizing that students who could speak well would achieve a better grade. Another participant shared an issue related to test anxiety: "I would like to take a test rather doing a presentation because I don't like to speak in front of people who watch me" (Libya, Pre-test).

Although the expressed attitudes toward the poster project were split between positive and negative, a clear majority, (79\%), believed that the project would be useful to them, which is a positive attitude. Table 12, below, shows participants' responses to the second open-ended question on the pre-test: Will giving a presentation be useful for your learning? How or how not? Nineteen participants (79\%) believed that the poster project would be useful for their learning. 
Table 12

Participants' Responses to the Question: Will giving a presentation be useful for your learning? How or how not?

\begin{tabular}{|c|c|c|c|c|c|c|}
\hline $\begin{array}{c}\text { Culture of } \\
\text { Learning }\end{array}$ & $\begin{array}{c}\text { Saudi } \\
\text { Arabia }\end{array}$ & $\begin{array}{c}\text { Chinese- } \\
\text { Speaking }\end{array}$ & Libya & Brazil & Kuwait & Total \\
\hline Useful & 5 & 3 & 4 & 4 & 3 & $\mathbf{1 9}$ \\
\hline Not Useful & 2 & 1 & 0 & 0 & 0 & $\mathbf{3}$ \\
\hline $\begin{array}{c}\text { "I don't } \\
\text { care" }\end{array}$ & 0 & 1 & 0 & 0 & 0 & $\mathbf{1}$ \\
\hline $\begin{array}{c}\text { Unanswered } \\
\text { Total }\end{array}$ & $\mathbf{8}$ & $\mathbf{5}$ & $\mathbf{4}$ & $\mathbf{4}$ & $\mathbf{3}$ & $\mathbf{2 4}$ \\
\hline
\end{tabular}

A majority from each culture of learning identified the poster project as being useful for their learning. The five participants who responded differently than "useful," including "not useful," "I don't care," or even left the question unanswered, were from Saudi Arabia and Chinese-speaking countries. This may indicate that participants from Saudi Arabia and Chinese-speaking countries maintained the most reservations about the poster project. The fourth research question asking, Is there a correlation between participants' attitudes toward the poster project and their cultures of learning? is thus relevant here because, although there is no apparent correlation between participants' beliefs about the usefulness of the poster projects and their cultures of learning, there may be a correlation between participants' positions of uncertainty and the cultures of learning in Saudi Arabia and Chinese-speaking countries. If previous experience is an indicator of 
confidence in a new assessment type, then participants' from Saudi Arabia and Chinesespeaking countries were already less likely to believe in the usefulness of the poster project.

Several participants seemed to be thinking ahead to future academic endeavors as they responded to the open-ended question. Practice for similar assignments in the future proved to be a theme in participants' responses. One wrote, "Yes, in regular class, almost every professor will give student group work and presentations so, I think practice presentation is useful for future" (Chinese-speaking, Pre-test). Another observed the authenticity of the assessment: "Yes, I think the presentation is a good way for learning and I will need this skill not only in the future but also every day that I express my opinion" (Brazil, Pre-test). A participant from Saudi Arabia saw the relevance of this assessment to his or her professional goals: "I think giving presentation always be useful for the learning because I have to find sources for my presentation and this will help me when I want to find sources for my researches" (Pre-test). One participant also thought the project was useful for learning, particularly for improving fluency: "Yes, it will be useful for me to give a presentation. I believe that speaking English fluently can be improved by giving presentations and answering the questions that are asked by the audience" (Libya, Pre-test). As mentioned earlier, Bloom's Taxonomy is explicitly taught in this particular course, and one participant was keen on its relevance to the poster project: "It'll be useful because I'll need to use all aspects of Bloom's Taxonomy" (Brazil, Pre-test). Even if some participants didn't feel happy or excited about doing the project, if they believed it was useful for their learning, that is a positive attitude. 
While some were eager to practice expressing their opinion, others did not have an opinion about the assignment: “To be honest, I don't know if this will be useful for my learning. I just follow what teacher says" (Chinese-speaking, Pre-test). This participant's response should serve as a reminder to teachers that some students are content to trust the teacher and others would rather defer to the teacher. Some participants did not believe that the poster project would be useful for their learning. One in particular thought it would be more useful to a lower level: "I think this is an old style [of] learning I mean this is can help students in the beginning of the new language not in level 5!!" (Saudi Arabia, Pre-test).

Even though when asked about their feelings toward the poster project versus a test, participants' expressed attitudes were split between positive and negative, many of them viewed the poster project as useful for their learning, that in itself is a positive attitude. A few students contested the validity of having a speaking component on a reading assessment, however, according to the rubric (see Appendix D), the oral presentation component of the rubric is concerned with the content of the presentation rather than speaking ability. The fact that so many participants anticipate having similar future assessments reflects the authenticity of the assessment.

\section{Research Question \#2: Is there a change in participants' attitudes after they complete the assessment? If so, what kind?}

In order to address this question, the mean attitude score from the pre-test was subtracted from the mean attitude score from the post-test for each participant to calculate an attitude gain score. A negative gain score indicates that a participant's attitude got 
worse while a positive gain score indicates a more positive attitude on the post-test. Responses to the fourth open-ended question on the post-test, Has your attitude about this poster project changed in any way? If so, how? provided qualitative insight into the quantitative findings.

Figure 1, below, shows the distribution of the positive and negative gain scores of the participants, who are grouped by their cultures of learning. The y-axis shows the amount of gain each participant experienced, and all the participants experienced a positive or negative gain of one point or less. So although the participants' attitude gains were very small, it is interesting to see the range of change as well as the distribution of the positive and negative attitude gains. The majority of the participants from each culture of learning experienced positive attitude gains. 


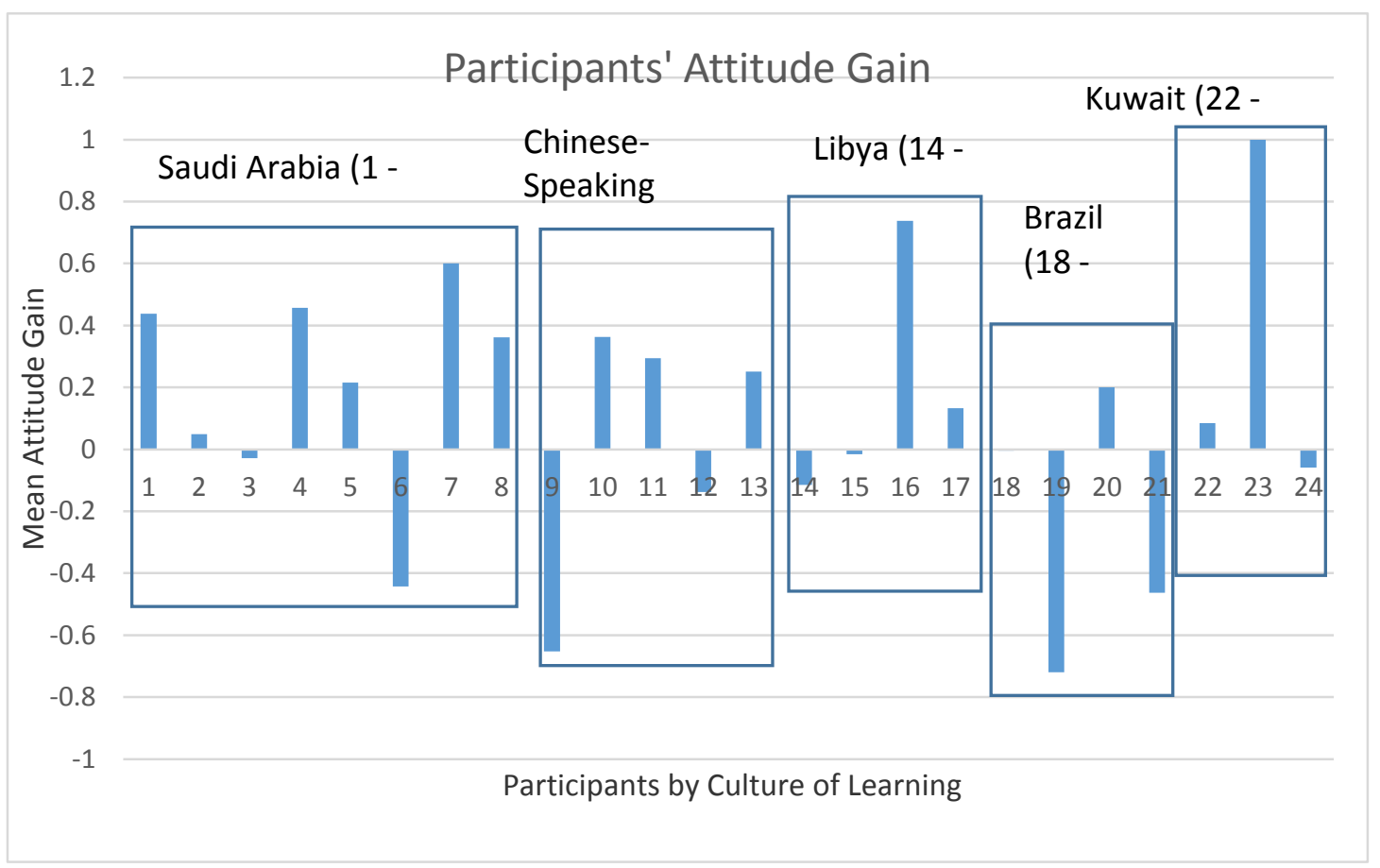

Figure 1

Participants' Attitude Gain

According to the quantitative data, participants were almost evenly divided for positive and negative gain. Fourteen participants $(58 \%)$ had a positive attitude gain whereas (42\%) showed a negative attitude gain. A paired t-test, run in SPSS, determined that these attitude gain scores were not statistically significant, $\mathrm{t}(23)=1.70, p=.11, r=$ 0.33. A lack of statistical significance for the attitude gain scores shows that although the scores indicated some kind of attitude gain, they were inconsequential.

Although there was no statistical significance present in attitude gain scores, did participants perceive an attitude gain? Close examination of the responses to the openended questions on the post-test revealed interesting and more specific results. Of particular relevance to this research question is the fourth open-ended question on the 
post-test which read: Has your attitude about this poster project changed in any way? If so, how? Table 13, below, clearly shows that the majority of the participants, (54\%), perceived an unchanged attitude about the assignment. Seven of the 24 participants, (29\%), did, however, report a change in attitude.

Table 13

Participants' Perceived Attitude Changes toward the Poster Project Based on the Question: Has your attitude about this poster project changed in any way? If so, how?

\begin{tabular}{|c|c|c|c|c|c|c|}
\hline & $\begin{array}{c}\text { Saudi } \\
\text { Arabia }\end{array}$ & $\begin{array}{c}\text { Chinese- } \\
\text { Speaking } \\
\text { Countries }\end{array}$ & Libya & Brazil & Kuwait & Total \\
\hline $\begin{array}{c}\text { Attitude } \\
\text { Change }\end{array}$ & 1 & 0 & 3 & 1 & 2 & $\mathbf{7}$ \\
\hline $\begin{array}{c}\text { No Attitude } \\
\text { Change }\end{array}$ & 4 & 4 & 1 & 2 & 1 & $\mathbf{1 2}$ \\
\hline $\begin{array}{c}\text { Remained } \\
\text { positive }\end{array}$ & 0 & 0 & 0 & 1 & 0 & $\mathbf{1}$ \\
\hline $\begin{array}{c}\text { Unanswered } \\
\text { Total }\end{array}$ & $\mathbf{8}$ & $\mathbf{5}$ & $\mathbf{4}$ & $\mathbf{4}$ & $\mathbf{3}$ & $\mathbf{2 4}$ \\
\hline
\end{tabular}

The question remains, in what direction did their attitudes change? It seems important to note that few participants qualified their answers beyond answering plainly, yes or no. The majority of those participants with positive responses explained their answer; whereas the majority of those with negative responses simply said, no. Six out of the seven participants who answered, yes, went on to explain a positive change in their attitudes. One participant described his or her positive attitude gain in detail: "Yes, I 
thought it's useless and has nothing to do in my subject but I found the [opposite]" (Kuwait, Post-test). Another wrote, “[My attitude] changed a little bit because I was thinking that it was very hard, but I was wrong” (Libya, Post-test). The qualification, "a little bit," is important here because it serves as a reminder that sometimes people become accustomed to new practices gradually. Other participants experienced a more drastic positive attitude gain, for example, "Yes, first I feel [scared] to fail or can't do it but, then I like the idea of our poster" (Saudi Arabia, Post-test). A participant from Brazil answered no and explained that his or her attitude had not changed because it had always been positive.

This qualification revealed a question about whether the negative responses indicated that the attitudes of those participants were positive and did not change or were negative and did not improve. I examined the pre- and post-tests for each participant and compared his or her expressed feelings on the pre-test with their response to the openended question on the post-test, Has your attitude about this project changed in any way? I was thus able to group the participants four ways, which are represented in Table 14 below. 
Table 14

Participants' Attitude Change Directions from Pre-Test to Post-Test

\begin{tabular}{|c|c|c|c|c|}
\hline $\begin{array}{c}\text { Positive } \rightarrow \\
\text { Positive }\end{array}$ & $\begin{array}{c}\text { Positive } \rightarrow \\
\text { Negative }\end{array}$ & $\begin{array}{c}\text { Negative } \rightarrow \\
\text { Negative }\end{array}$ & $\begin{array}{c}\text { Negative } \rightarrow \\
\text { Positive }\end{array}$ & Missing Data \\
\hline 7 & 0 & 6 & 6 & 5 \\
\hline
\end{tabular}

Table 14, above, shows that, although $50 \%$ of the participants reported having no attitude change about the poster project, $54 \%$ of all participants did, in fact, leave with a positive attitude about the poster project. Thirteen participants either had positive attitudes that remained unchanged or had a positive attitude gain about the poster project, while six participants maintained a negative attitude toward the poster project. Interestingly, and fortunately, none of the participants reported a negative change of attitude. Four participants skipped the question and one participant provided an illegible answer, so it remains unknown what attitude these five participants had about the poster project. Therefore, $68 \%$ of the 19 participants who answered the question about their perceived attitude gain on the post-test had a positive attitude about the poster project.

Another possible relationship needs to be considered to address the fourth research question: participants' cultures of learning and their attitude gain. There was little difference between the mean attitude scores for the pre-test and the post-test. As Table 15 , below, shows, there were 15 participants with a positive mean attitude score on the post-test, an increase of one from the pre-test. Six participants had a neutral mean 
attitude score on the post-test, again an increase of one from the pre-test. The only two participants who maintained a negative mean attitude score were from Saudi Arabia.

Table 15

Participants' Mean Attitude Scores on the Post-Test

\begin{tabular}{|c|c|c|c|c|c|c|c|c|c|c|c|c|}
\hline \multicolumn{13}{|c|}{ Post-Test Mean Attitude } \\
\hline & \multicolumn{5}{|c|}{ Negative } & \multirow{2}{*}{\begin{tabular}{|c|} 
Neutral \\
5
\end{tabular}} & \multicolumn{5}{|c|}{ Positive } & \multirow{2}{*}{$\begin{array}{l}\begin{array}{l}\text { Overall } \\
\text { Total }\end{array} \\
\end{array}$} \\
\hline $\begin{array}{l}\text { Culture } \\
\text { of } \\
\text { Learning }\end{array}$ & $\begin{array}{c}\text { Total } \\
\text { Negative }\end{array}$ & 1.0 & 1.5 & 2.0 & 2.5 & & 3.5 & 4.0 & 4.5 & 5.0 & $\begin{array}{c}\text { Total } \\
\text { Positive }\end{array}$ & \\
\hline $\begin{array}{l}\text { Saudi } \\
\text { Arabia }\end{array}$ & 2 & 0 & 0 & 0 & 2 & 3 & 2 & 1 & 0 & 0 & 3 & 8 \\
\hline $\begin{array}{l}\text { Chinese- } \\
\text { Speaking }\end{array}$ & $\mathbf{0}$ & 0 & 0 & 0 & 0 & 2 & 1 & 2 & 0 & 0 & 3 & 5 \\
\hline Libya & $\mathbf{0}$ & 0 & 0 & 0 & 0 & $\mathbf{0}$ & 3 & 1 & 0 & 0 & 4 & 4 \\
\hline Brazil & $\mathbf{0}$ & 0 & 0 & 0 & 0 & 1 & 1 & 2 & 0 & 0 & 3 & 4 \\
\hline Kuwait & $\mathbf{0}$ & 0 & 0 & 0 & 0 & $\mathbf{0}$ & 2 & 1 & 0 & 0 & 3 & 3 \\
\hline
\end{tabular}

Although only two participants maintained a mean negative attitude score on the post-test, some participants experienced small decreases in their mean attitude score from the pre-test to the post-test, in other words, negative gain. The amount of gain, both negative and positive, was slight, one point or less, but attitudes do not change overnight. Table 16, below, shows that six participants experienced negative attitude gain, three had no gain, and 15 participants had a positive attitude gain. All participants from Kuwait either experienced no gain or positive gain, and surprisingly, six of the eight participants from Saudi Arabia had positive attitude gain. Another surprise was the split between the Brazilian participants. Two participants each had positive and negative attitude gain. 
The Chinese-speaking participants were also split between positive and negative gain.

Two participants from Libya had positive attitude gain while one had negative gain and another had none. Although there is no clear evidence of a relationship between participants' cultures of learning and their attitudes about the poster project, the participants from Saudi Arabia had the highest percentage of participants with positive attitude gain.

Table 16

Participants’ Attitude Gain Scores

\begin{tabular}{|c|c|c|c|c|c|c|c|c|c|c|c|c|}
\hline \multicolumn{13}{|c|}{ Attitude Gain } \\
\hline & \multicolumn{5}{|c|}{ Negative Gain } & \multirow{2}{*}{\begin{tabular}{|c|}
$\begin{array}{c}\text { No } \\
\text { Gain }\end{array}$ \\
0
\end{tabular}} & \multicolumn{5}{|c|}{ Positive Gain } & \multirow{2}{*}{\begin{tabular}{|l} 
Overall \\
Total
\end{tabular}} \\
\hline $\begin{array}{l}\text { Culture } \\
\text { of } \\
\text { Learning }\end{array}$ & $\begin{array}{c}\text { Total } \\
\text { Negative } \\
\text { Gain }\end{array}$ & -1.0 & -0.75 & -0.5 & -0.25 & & +0.25 & +0.5 & +0.75 & +1.0 & $\begin{array}{c}\text { Total } \\
\text { Positive } \\
\text { Gain }\end{array}$ & \\
\hline $\begin{array}{l}\text { Saudi } \\
\text { Arabia }\end{array}$ & 1 & 0 & 0 & 1 & 0 & 1 & 2 & 4 & 0 & 0 & 6 & 8 \\
\hline $\begin{array}{l}\text { Chinese- } \\
\text { Speaking }\end{array}$ & 2 & 0 & 0 & 1 & 1 & $\mathbf{0}$ & 2 & 1 & 0 & 0 & 3 & 5 \\
\hline Libya & 1 & 0 & 0 & 0 & 1 & 1 & 1 & 0 & 1 & 0 & 2 & 4 \\
\hline Brazil & 2 & 0 & 1 & 1 & 0 & $\mathbf{0}$ & 1 & 1 & 0 & 0 & 2 & 4 \\
\hline Kuwait & $\mathbf{0}$ & 0 & 0 & 0 & 0 & 1 & 1 & 0 & 0 & 1 & 2 & 3 \\
\hline
\end{tabular}

\section{Research Question \#3: What are the positive and/or negative washback effects of the} alternative assessment on the learners?

The washback effects, which can be harmful or beneficial, are the effects of the poster project on the learners. Therefore, in order to address this question, it was 
important to consider what the participants thought they learned and what they thought was the learning goal of the poster project. Responses to all of the open-ended questions on the post-test were considered in the findings. Participants' responses revealed six positive washback effects: positive attitude toward the poster project, self-confidence, accurate interpretation of the learning goal(s), identification of something learned, community building and/or cultural exchange, and deeming the assessment useful.

Positive attitude toward the poster project. Having a positive attitude toward the poster project is considered a positive washback effect because it benefits the learner for future assessments, namely poster projects. The participants' next experience with a poster project, or possibly another similar alternative assessment, will likely be informed, at least initially, by this experience. One participant shared his or her positive feelings about doing the poster project: "It was fun designing a poster which presented my home country. It took an hour. I feel proud and happy" (Kuwait, Post-Test). Two participants expressed positive feelings about the prospect of doing another poster project in the future saying, "I would feel happy because it is a good thing that we try a new ways to learn" (Libya, Post-Test) and "I will feel good because it would be easier than the first time" (Libya, Post-Test). These positive attitudes may be starting points for some of the participants when they are assigned another alternative assessment like a poster project. However, if they do not feel happy or proud, maybe they will at least feel confident. Self-confidence. Self-confidence, the second positive washback effect, was a theme that appeared in responses to different questions on the post-test. The first openended question on the post-test asked, In the future, how would you feel about designing 
a poster to present information? One participant answered, "I would feel more comfortable and confident because it will not be the first time to design a poster" (Libya, Post-test). Other participants responded to the same question with confidence: "I'll go for it" (Kuwait, Post-test) and "I think that I can do a poster very easy, and I can do a great job" (Libya, Post-test). Confidence also came up in both the pre-tests and post-tests in response to the fifth question: In your opinion, what is/was the learning goal for this poster project? One responded on the post-test, "The goal was to make sure that everyone has [confidence] in his/herself to present their information" (Libya, Post-test). On the pre-test, in response to the fourth question, What will you learn as a result of this poster project? a participant said, "I'm going to learn how to be more confident" (Saudi Arabia, Pre-test). A few participants used confidence to justify the usefulness of the assessment on the pre-test in answer to the question, Will giving a presentation be useful for your learning? "Yes, it gives me the [confidence] to speak and reach the information to the audience" (Saudi Arabia, Pre-test). In response to the same pre-test question, participants from Kuwait said, "Well, it will help indirectly on my self-confidence" and "Yes, it makes me more fluent and confident in English." To the same question, a Chinese-speaking participant responded, "Yes. It will built my confident to speak English" (Pre-test).

Accurate interpretation of the learning goal. The third positive washback effect was the accurate interpretation of the learning goal. All participants were provided the learning goal at the top of the assignment handout for the poster project as the "purpose" of the assignment, however, there was a variety of answers from participants about what 
they thought was the learning goal of the project. According to the handout, the purpose of the assessment was 'to assess students' ability to apply themes from a full-length nonfiction text to familiar experiences or areas of interest using accurate, academic English" (see Appendix D). During the instructor's introduction to the poster project, she asked the class, "What kind of critical thinking is needed for this poster?" Students around the room volunteered the answers, "create" and "apply." In an interview with the instructor after the projects were finished, she confirmed that application was her first goal, but she also said that another goal was to give students practice with and exposure to alternative assessments for their higher level critical thinking skills.

Only responses to the fifth open-ended question on the post-test asking, In your opinion, what was the learning goal for this poster project? were used to define participants' perceived learning goals. Several participants, though not all, identified some kind of application or connection as being at least one of the learning goals for the project. One participant wrote that the learning goal was "to find way to connect our experience with information from the book that we already read" (Saudi Arabia, Posttest). Mentioning "Bloom's Taxonomy" or "critical thinking” were also considered accurate interpretation of the learning goal. For example, one participant wrote, "The learning goal was to apply our critical thinking skills to different cultures" (Brazil, Posttest). Another participant identified the conciseness of the project by summing up the learning goal thus: “Apply Bloom's Taxonomy in one project” (Libya, Post-test?). Table 17, below, shows the breakdown of how many participants identified different learning goals in their responses on the post-test. "Apply" or "Connect" were identified as the 
learning goal eight times, "Bloom's Taxonomy" or "create" were identified four times, and these are all considered to be accurate interpretations of the learning goal. Most participants from Libya (3/4), Brazil (3/4), and Chinese-speaking countries (3/5) identified these learning goals.

Table 17

Participants' Perceived Learning Goals According to Post-Test Open-Ended Responses

\begin{tabular}{|c|c|c|c|c|c|c|}
\hline Learning Goals & $\begin{array}{c}\text { Saudi } \\
\text { Arabia }\end{array}$ & $\begin{array}{c}\text { Chinese- } \\
\text { Speaking } \\
\text { Countries }\end{array}$ & Libya & Brazil & Kuwait & Total \\
\hline Apply/Connect & 1 & 2 & 1 & 3 & 1 & $\mathbf{8}$ \\
\hline $\begin{array}{c}\text { Bloom's } \\
\text { Taxonomy/Create }\end{array}$ & 0 & 1 & 2 & 1 & 0 & $\mathbf{4}$ \\
\hline Learn about the book & 3 & 0 & 1 & 0 & 0 & $\mathbf{4}$ \\
\hline $\begin{array}{c}\text { Practice Presentation } \\
\text { Have Confidence }\end{array}$ & 0 & 0 & 1 & 0 & 0 & $\mathbf{1}$ \\
\hline "Combine fun and \\
learning"
\end{tabular}


Awareness of learning. The fourth positive washback effect was determined by the participants' ability to identify something that he or she had learned, including the improvement of a skill. Even if participants did not learn how to apply information or use critical thinking as the instructor hoped, if the assessment facilitates or reinforces learning, that is a positive washback effect. This washback effect was identified in participants' responses to the second open-ended question on the post-test: Did you learn something from doing this assignment? If so, what? Although three participants said they did not learn anything and two did not answer the question, most participants provided insightful answers, which are organized in Table 18 below. Several students claimed to have learned a variety of information and skills from doing the poster project. 
Table 18

Participants' Claims of Learning According to Post-Test Open-Ended Responses

\begin{tabular}{|c|c|c|c|c|c|c|}
\hline What did you learn? & $\begin{array}{c}\text { Saudi } \\
\text { Arabia }\end{array}$ & $\begin{array}{c}\text { Chinese- } \\
\text { Speaking } \\
\text { Countries }\end{array}$ & Libya & Brazil & Kuwait & Total \\
\hline $\begin{array}{c}\text { How to Design a } \\
\text { Poster }\end{array}$ & 1 & 1 & 0 & 1 & 1 & $\mathbf{4}$ \\
\hline $\begin{array}{c}\text { Content Knowledge } \\
\text { Improve Speaking } \\
\text { Skills }\end{array}$ & 1 & 3 & 0 & 2 & 0 & $\mathbf{6}$ \\
\hline $\begin{array}{c}\text { Practice Presentation } \\
\text { Be Creative }\end{array}$ & 0 & 1 & 1 & 0 & 0 & $\mathbf{2}$ \\
\hline $\begin{array}{c}\text { How to Apply } \\
\text { Information }\end{array}$ & 0 & 0 & 0 & 1 & 2 & $\mathbf{3}$ \\
\hline Something New & 1 & 0 & 1 & 1 & 0 & $\mathbf{3}$ \\
\hline Unclear Answer & 1 & 0 & 0 & 0 & 0 & $\mathbf{1}$ \\
\hline $\begin{array}{c}\text { Left Answer Blank } \\
\text { Unter| }\end{array}$ & 1 & 1 & 0 & 0 & 0 & $\mathbf{2}$ \\
\hline
\end{tabular}

There were six occurrences of participants identifying content knowledge about their poster's topic. For example, two participants from Brazil wrote, "I learned more about gentrification processes" (Brazil, Post-test) and "I learned some characteristics from the city I came from that I did not know" (Brazil, Post-test). In contrast, there were 16 occurrences of learning or refining a skill such as public speaking, designing a poster, creativity, application, and giving a presentation. One participant gained a useful skill transferrable to future assignments and professional endeavors: "I used a computer program that could be very useful in other activities, and I learned to organize my poster" 
(Brazil, Post-test). Another participant gained practice in clearly expressing and organizing ideas: "I learned how to be creative in making my ideas clear and explicit. Additionally, the poster project improved my ability to do a presentation" (Libya, Posttest).

If participants believed they improved in their skills, be it speaking, English language, presentation, or other skills, that was interpreted as an awareness or identification of something learned. Although some participants did not like the speaking component of the assessment, others appreciated the improvement such practice afforded: "I think that I have learned how to make a poster and improve my speaking skill" (Chinese-speaking, Post-test).

Community building and cultural exchange. The most surprising positive washback effect was mentioned by only a handful of students: community building and cultural exchange. This theme was uncovered in different contexts both on the pre-test and on the post-test. On the post-test, one participant identified the learning goal as "helping us to understand our class" (Chinese-speaking, Post-test). This theme did not come up elsewhere in responses on the post-test, however, it was a potential washback effect because two other participants anticipated on the pre-test that the learning goal was to "help community" (Chinese-speaking, Pre-test) and "exchange some understandings and knowledge about different cultures between our classmates" (Libya, Pre-test). On the post-test, these participants identified the learning goal as having to do with application: "use the knowledge from book to our life" (Chinese-speaking, Post-test) and "testing our ability to understand the book" (Libya, Post-test). Although responses in the 
post-test provide minimal support for this washback effect, it is interesting that some participants anticipated this effect on the pre-test. And although it was not explicitly written about in responses on the post-test, I observed cultural exchange during the presentations as several participants shared with their classmates about their own culture or one they spent time learning about. One participant commented on the post-test: "It was nice to do this assignment because I can [share] some info about my culture" (Saudi Arabia, Post-test). During the in-class activity, in which students scored previous posters with the rubric, I overheard some discussing their ideas for their poster projects and giving one another advice. Instances of peer support like this one may have fostered a sense of community building generating a positive washback effect.

Deeming the assessment useful. Finally, the sixth positive washback effect was qualified by participants' deeming the poster project as useful on the post-test. The second research question examined participants' opinions regarding the usefulness of the assessment, and the majority of participants expected the assessment to be useful. According to participants' responses on the post-test, the assessment was useful for the participants' learning because 17 participants identified specific things they learned as well as skills they honed. One participant even wrote, "I learned how I can reach my idea to other student easily by putting some pictures, phrases, etc. I think this poster is very useful" (Libya, Post-Test).

Negative attitude toward the poster project. The three negative washback effects included a negative attitude toward the poster project, misidentification of the learning goal, and the assessment is not considered useful. To address the first of these, 
responses to the third open-ended question on post-test, In the future, how would you feel about designing a poster to present information? revealed that most participants offered a positive or neutral response. However, one participant responded: "I will be angry when I have like this test" (Saudi Arabia, Post-test), and another said, "I would not like, but is better than a test" (Brazil, Post-test). Like the first positive washback effect, positive attitude toward the poster project, the attitude of the learner is an important washback effect because it will likely be his or her starting point for the next poster project, or other alternative assessment.

Misidentification of the learning goal. Misidentification of the learning goal is the foil to the positive washback effect, accurate identification of the learning goal. Although most participants identified the learning goal of the project as having something to do with application, others focused on other goals, and these could easily have been peripheral goals of the project, but they were not the focus of the assessment. For example, some participants thought the learning goal of the poster project was "to see we understand the book or not" (Saudi Arabia, Post-test) and "gots more grade" (Chinesespeaking, Post-test). Gaining familiarity with alternative assessments was a peripheral goal the instructor had for the students, and a couple participants identified it: "It was how to present my poster" (Saudi Arabia, Post-test); "Maybe to see the student if they understand the book they had read or to make the student well prepared to present any poster in future" (Saudi Arabia, Post-test). I would not say that these were not goals for the poster project, however, they were not the primary learning goal as the instructor and several participants identified it. 
Deeming the assessment not useful. The final negative washback effect is the reverse for the sixth positive washback effect, the assessment is deemed useful. In response to the second open-ended question on the post-test, Did you learn something from doing this assignment? If so, what? three participants from Saudi Arabia said they did not learn anything, and one of them qualified the response: "No, just designing" (Post-test). These three participants did not find the assessment useful for their learning, which shows a kind of negative washback.

Relationship between cultures of learning and washback effects. Although there were no clear patterns observed between participants' cultures of learning and different kinds of positive washback, it was evident that most participants who may have experienced some negative washback from the poster project were from Saudi Arabia. The lack of prior experience with alternative assessments may have been a contributing factor as Saudi Arabian participants reported the least amount of prior experience with alternative assessments in their home culture of learning.

\section{Research Question \#4: Is there a relationship between the participants' attitudes toward the poster project and their cultures of learning?}

This question has already been addressed somewhat within the results of the previous three research questions. There were a couple of questions, not yet addressed, in the Likert-scale portion of the instruments designed to discern participants' feelings about trying new ways to learn, or their innovativeness. Table 19, below, shows that, overall, nine participants experienced no innovativeness gain, and 12 participants, (50\%), experienced a positive innovativeness gain. Only three participants experienced a 
negative innovativeness gain, and all of them were from Saudi Arabia. As the table below shows, the group that experienced no gain and the group that experienced positive gain were represented by all cultures of learning. Most participants from Brazil and Kuwait remained the same, while most from Libya and Chinese-speaking countries had positive innovativeness gain. Saudi Arabian participants were the only group that was split between negative gain, no gain, and positive gain. At this point, the group from Saudi Arabia stands out amongst the others, however, this group also had the largest number of all the groups, which may have provided a better survey.

Table 19

Participants' Innovativeness Gain Scores

\begin{tabular}{|l|c|c|c|c|c|c|c|c|c|c|c|c|c|}
\hline \multicolumn{10}{|c|}{ Innovativeness Gain } \\
\hline & \multicolumn{9}{|c|}{ Negative Gain } & $\begin{array}{c}\text { No } \\
\text { Gain }\end{array}$ & \multicolumn{7}{c|}{ Positive Gain } & $\begin{array}{c}\text { Overall } \\
\text { Total }\end{array}$ \\
\hline $\begin{array}{l}\text { Culture } \\
\text { of } \\
\text { Learning } \\
\begin{array}{l}\text { Total } \\
\text { Gain }\end{array}\end{array}$ & -2.0 & -1.5 & -1.0 & -0.5 & 0 & +0.5 & +1.0 & +1.5 & +2.0 & $\begin{array}{c}\text { Total } \\
\text { Positive } \\
\text { Gain }\end{array}$ & \\
\hline $\begin{array}{l}\text { Saudi } \\
\text { Arabia }\end{array}$ & $\mathbf{3}$ & 0 & 1 & 1 & 1 & $\mathbf{2}$ & 1 & 0 & 1 & 1 & $\mathbf{3}$ & $\mathbf{8}$ \\
\hline $\begin{array}{l}\text { Chinese- } \\
\text { Speaking }\end{array}$ & $\mathbf{0}$ & 0 & 0 & 0 & 0 & $\mathbf{1}$ & 4 & 0 & 0 & 0 & $\mathbf{4}$ & $\mathbf{5}$ \\
\hline $\begin{array}{l}\text { Libya } \\
\text { Brazil }\end{array}$ & $\mathbf{0}$ & 0 & 0 & 0 & 0 & $\mathbf{1}$ & 2 & 1 & 0 & 0 & $\mathbf{3}$ & $\mathbf{4}$ \\
\hline Kuwait & $\mathbf{0}$ & 0 & 0 & 0 & 0 & $\mathbf{3}$ & 0 & 1 & 0 & 0 & $\mathbf{1}$ & $\mathbf{4}$ \\
\hline
\end{tabular}

The Likert-scale portion of the questionnaires also included a few questions designed to elicit what participants thought about the washback effects of the poster 
project on their learning. The mean score for the question domain, "Learning," was compared with the participants' cultures of learning. Overall, as shown in Table 20 below, 14 participants, (58\%), experienced a negative learning gain, and seven participants experienced a positive learning gain. Five participants remained the same, three of which were from Saudi Arabia. Surprisingly, all of the Libyan participants experienced negative learning gain. The surprise is due, in part, to the tone of the openended responses written by the Libyan participants. Their responses were very thoughtful, articulate, and primarily positive.

Table 20

Participants' Learning Gain Scores

\begin{tabular}{|c|c|c|c|c|c|c|c|c|c|c|c|c|}
\hline & & & & & Lear & ning & Gain & & & & & \\
\hline & & egativ & Gail & & & No & & & sitive & Gain & & Overall \\
\hline $\begin{array}{l}\text { Culture } \\
\text { of } \\
\text { Learning }\end{array}$ & $\begin{array}{c}\text { Total } \\
\text { Negative } \\
\text { Gain }\end{array}$ & -2.0 & -1.5 & -1.0 & -0.5 & 0 & +0.5 & +1.0 & +1.5 & +2.0 & $\begin{array}{c}\text { Total } \\
\text { Positive } \\
\text { Gain }\end{array}$ & \\
\hline $\begin{array}{l}\text { Saudi } \\
\text { Arabia }\end{array}$ & 3 & 0 & 1 & 1 & 1 & 3 & 1 & 0 & 0 & 1 & 2 & 8 \\
\hline $\begin{array}{l}\text { Chinese- } \\
\text { Speaking }\end{array}$ & 3 & 0 & 1 & 0 & 2 & 0 & 2 & 0 & 0 & 0 & 2 & 5 \\
\hline Libya & 4 & 0 & 0 & 1 & 3 & $\mathbf{0}$ & 0 & 0 & 0 & 0 & 0 & 4 \\
\hline Brazil & 2 & 0 & 0 & 1 & 1 & 1 & 1 & 0 & 0 & 0 & 1 & 4 \\
\hline Kuwait & 1 & 0 & 0 & 0 & 1 & 1 & 1 & 0 & 0 & 0 & 2 & 3 \\
\hline
\end{tabular}

Finally, there were four Likert-scale questions about participants' experience with alternative assessments, like the poster project, in their home country. Although 
participants' previous experience was ascertained through background questions included on the pre-test, these Likert-scale questions provided another way to show relationships between the participants' cultures of learning and their previous experience. Obviously, all of the participants, regardless of their culture of learning, had a gain in experience with alternative assessments because they did the poster project. However, is there a relationship between participants' previous experience and their poster project grades? Because the data were normally distributed, a paired samples t-test was conducted to test for a possible correlation between the participants' previous experience and their poster project grades. The test, run in SPSS, revealed statistical significance: $\mathrm{t}(22)=76.59, p=$ 0.00. Therefore, students who had previous experience with alternative assessments, like the poster project, scored higher on their poster projects, affirming the old adage that practice makes perfect. This finding should affirm ESL instructors in their own implementation of alternative assessments as it shows that students fare better as they gain more experience. 


\section{Discussion}

The use of mixed methods for this study proved valuable as each research question was addressed because there was a consistent mismatch between the findings of the quantitative and qualitative data regarding participants' attitudes. For example, quantitative results revealed that, of the 24 participants, $16(67 \%)$, had a positive mean attitude score (above the neutral score of 3 on a scale of 1 to 5) on the pre-test. However, according to responses to the open-ended questions, participants' expressed attitudes were split. The open-ended responses also revealed that a majority (79\%) believed that the assessment would be useful for their learning in the future, which indicates a positive attitude. It is possible that the Likert-scale questions were able to uncover some subconscious attitudes of the participants whereas responses to the open-ended questions revealed attitudes participants were aware of or chose to express. However, even if they expressed positive feelings about the poster project and had positive mean attitude scores for their post-tests, it is still possible that they may have deeply rooted or long kept beliefs about the learning value of taking a test as compared with something like doing a poster project. It is also possible that the questions failed to capture the beliefs held by the participants.

As so many participants had some kind of positive attitude toward the poster project, it was preferable that few participants reported having an attitude change. Quantitative data revealed no statistically significant attitude gain, and the qualitative data confirmed it. This was not a surprising finding because, as Nkosana (2009) suggested, attitudes are related to beliefs, and beliefs are often deeply rooted and take 
time to change. However, close inspection of how participants responded to open-ended questions on both the pre- and post-tests revealed that, although there were few attitude changes, participants' attitudes were mostly positive. In fact, some participants reported having a positive attitude gain, even though the difference between the mean attitude scores from the pre- and post-tests were not statistically significant. Once again, there was a mismatch between participants' reports and the quantitative data. It may be that the Likert-scale questions were not able to capture the changes in participants' attitudes. Participants' reports were in line with Lambert's (2008) experience implementing poster presentations as a final assessment: "The activity proved popular with the students...feedback was generally positive, with many learners saying how much they enjoyed it, despite expressing initial misgivings about the task" (p. 7). Participants of this study also expressed initial misgivings about the poster project, and although participants of the present study did not have a statistically significant attitude gain, there was more positive feedback on the post-test responses than on the pre-test.

Agency may have also contributed to positive washback effects. It is possible that the format of individual poster designs and presentations facilitated more learner autonomy and provided students with a more active role in their own learning goals. According to Barfield (2003) and Bourner et al. (2000), project learning and other performance-based assessments employ the teachers as facilitators and mentors while the students take an active role in their learning processes promoting creativity, critical thinking, and experiential learning (as cited in Burkšaitienė \& Teresevičienè, 2008). This may be one of the best reasons to implement alternative assessments in the ESL 
classroom: they promote learner autonomy and invite students to take an active role in achieving their language learning goals. Participants' poster designs and topic focuses revealed that they saw the poster project as an opportunity to create something personally meaningful. The meaningfulness of the poster projects may have contributed to the participants' beliefs that the poster project was useful for their learning.

According to Brown \& Hudson (1998), alternative assessments must require students to perform, create, produce, or do something; they must use real-world contexts or simulations (p. 654). The AAR students used creativity and application to produce posters, and although the instructor advised students that the posters should speak for themselves, students also had to "perform" for their peers when they presented their posters. Because "numerous contrasts characterize learning across cultures, and many of these have implications for assessment," this study was designed to address students' attitudes toward this particular alternative assessment, and thereby assess the washback effects of the assessment on the learners (Kopriva, 2008, p. 23). This study confirms three of the washback hypotheses developed by Alderson \& Wall (1993), specifically that a test will influence learning, the degree and depth of learning, and the attitudes to content, method, etc. of teaching and learning (as cited in Alderson \& Hamp-Lyons, 1996, pp. 281-282). Because so many participants claimed to have learned something from the poster project, it is clear that the poster project influenced learning, and for the most part, influenced it positively. The degree and depth of learning were also influenced by the poster project. Based on participants' responses to open-ended questions on the pre- and post-tests, there were varying degrees of learning. However, the instructor noted 
that the poster project was a vehicle for really deep language learning when a student demonstrated mastery of application after expressing his or her research through a variety of mediums: written, verbal, and graphic. The agency of the students seems to be key in achieving this depth of learning. The students who want to ask questions and invest time in learning, in using the poster project as a vehicle for learning, seem to achieve a deeper learning experience. However, for other students who rushed their projects or did not ask their questions, the possibly unfamiliar nature of the poster project may have limited their learning. Though the poster project's design certainly fosters a deep level of learning, it is important to remember that for those students who are resistant to a new assessment format, the poster project may limit their depth of learning.

Alderson \& Wall's final hypothesis addressed the influence tests have on attitudes to content, methods, etc. It has been argued by Cheng and Curtis (2004) that when teachers and learners have a positive attitude toward the assessment, positive washback effects will be generated (as cited in Hung, 2012, p. 27). This poster project had several positive washback effects on the participants of this study, which may be due in part to the positive attitudes expressed by both the teacher and the learners. The instructor has assigned the poster project several times, and her positivity about it was evident when she presented it to the class that was the context for this study. Nkosana (2009) made a distinction between perceptions and attitudes. As mentioned in the Literature Review, perceptions are susceptible to outside forces, characterized by words like impression. Attitudes, on the other hand, are like beliefs. Therefore, the instructor's positivity may have affected participants' perceptions more than their attitudes. On the pre-test, several 
participants expressed positive feelings and anticipation for what they would learn from doing the poster project. Attitudes and washback are inevitably tied, and the positive attitudes expressed by the instructor and the participants may have made the participants more likely to experience positive washback effects of the poster project. For example, several of the participants were able to accurately identify a goal of the assessment as being able to apply what they read in the book to the topic of their poster. A few participants recognized that the poster presentations facilitated a kind of community experience and cultural exchange, as several participants chose to use the poster project as a platform for sharing about their home country. The fact that "[test takers] do not view tests as useful tools for learning and note that tests are detached from 'real life' knowledge and performance" reveals some assessments are having negative washback effects on learning (Shohamy, 2001, p. 13). Thus, it can be inferred that the reverse is true: test takers' review of an assessment as being useful is indicative of positive washback. The variety of what participants' reported to have learned from doing the poster project reflects the variety of learners who participated. The poster project lends itself to a variety of learning outcomes due to the autonomy of narrowing a topic and creating a poster.

Another important washback effect on the participants was an increase in selfconfidence. The majority of participants believed at the outset of the poster project that it was useful for their learning, and several comments pointed to the authenticity of the assessment because it is becoming a widely used assessment format in American higher education. With an awareness that more poster projects may be assigned in the future, 
the reported increase in self-confidence is all the more meaningful. Assessment measures should be tools that promote and reinforce learning, and reports of increased selfconfidence suggest that the poster project was successful in doing so. The participants' confidence may also reflect a sense of success regarding the poster projects. Their confidence and success, perceived or real, indicates that the participants were wellsupported. Having implemented poster presentations in EFL classes, Lambert (2008) said,

Providing learners with sufficient advance preparation, as well as support in the shape of familiar format, will reduce anxiety and allow them to perform to the best of their abilities. In terms of face validity, clear instructions and unambiguous items let students know exactly what is being tested and thus help them to perceive the test as valid. (p. 2)

In line with this recommendation, the instructor of this AAR course lined the classroom walls with posters done by previous classes for students to score using the provided rubric, which was included in the assignment handout. The assignment handout (see Appendix D) is supportive and clear, stating the learning goal, the expectations, as well as providing the instructor's grading rubric. This activity may have contributed to the attitudes of the participants, especially if viewing real examples did indeed reduce anxiety, as suggested by Lambert. Lambert also provided previous examples for the class to view prior to the assessment. He said, "the visual element provided something more concrete to focus on" and "gives a clear picture of the standard the students are working 
toward" (2008, p. 7). The same goal was in mind when the instructor included this activity of scoring previous posters: provide students with examples and set a standard.

However, most students did not rise to meet that standard, as expressed by the instructor in an interview. Possible contributing factors to this outcome may include the fact that is was Summer term, students' level of interest in the text, or even the amount of time students' gave to working on the poster. Summer terms are usually condensed and intensive times of study typically taken advantage of by students trying to get ahead or trying to catch-up. This can lead to a classroom made up of both high and low achievers, creating a gap in the middle. There are also plenty of distractions in the summer, at least in the Pacific Northwest, what with more pleasant weather and a plethora of interesting activities. One participant wrote about his or her experience working on the poster: "It was easy. I didn't spend much time on it. I just did it in the night before. I feel like I would have done better if I spend some time on it" (Saudi Arabia, Post-test). Several of the participants, as I heard them say during my classroom observations, were taking at least one other course concurrently with AAR. The intensive and fast-paced nature of this eight week summer course may have also contributed to the limited amount of time some of the participants invested in their poster projects.

There are several possible reasons, however, for some participants' dislike of the poster project that may not be specifically related to the design of the assessment. More than one participant expressed dislike for the text used in AAR course: "I feel nervous about [the poster project] because the book that in reading is so boring for me" (Saudi Arabia, Pre-test). This response serves as a reminder that materials can affect the 
washback of assessments on learners, not just the assessment in isolation. There are three different non-fiction books on rotation for the AAR course, in case, for example, a student should repeat the course. Of the three rotating books, the instructor told me, Travel as a Political Act, is the least popular book. It is possible that another class using one of the other two books, would have provided different data.

Most of the participants who may have experienced negative washback effects from the poster project were from Saudi Arabia. Participants from Saudi Arabia also reported the least amount of previous experience with alternative assessments in their home learning culture, as compared with the other participants, which may have contributed to the washback effects. The statistical significance between the participants' previous experience and their poster project grade indicates that experience may also have an impact on washback. Experience leads to familiarity, which is comfortable, and comfort may generate positive attitudes.

Participants' attitudes and their cultures of learning were focal points of this study. However, there was no evidence of a relationship between participants' cultures of learning and their attitude gains. Participants' scores regarding their innovativeness and learning were contradictory. The vast majority of participants $(88 \%)$ either remained positive or had a positive gain in their attitudes toward trying new ways of learning. A small majority (58\%), however, had a negative gain for the learning value of the poster project. Although after doing the poster project, most of them were willing to try new ways to learn, perhaps they may not yet believe those new ways are valuable for learning. They may still believe that learning is best demonstrated or most effectively gained on a 
traditional paper and pencil test. The fact that such a high percentage of participants were willing to try new ways to learn is a step in a positive direction, and because so many participants reported having learned something from the poster project, I believe their beliefs about the effectiveness of alternative assessments for learning will come with time and experience. 


\section{Conclusion}

The goal of this study was to understand how a class made up of students from different learning cultures approach an alternative assessment, especially if their prior experience with alternative assessments is limited. The attitudes of the participants regarding a poster project before and after its execution were the focal point of the study. The findings revealed that several participants began with positive attitudes about the poster project, and the majority of participants indicated positive attitudes after the poster project was completed. Their positive attitudes may have resulted from a positive experience doing the poster project. Open-ended responses from participants provided evidence for a variety of positive washback effects from this particular alternative assessment, including self-confidence and accurate identification of the learning. My inclass observations provided insightful data that enriched the details of this study. Had I not been in the room with participants, my understanding of the poster project would have been limited, and I would have missed seeing and hearing students' initial reactions to the assignment, their questions when looking at sample posters and how they supported one another in their poster projects.

\section{Pedagogical Implications}

One of my personal goals for this study was to encourage ESL teachers not to shy away from alternative assessments, especially if they replicate the kinds of assignments their students will likely encounter in their mainstream classes. While initially getting to know the instructor of the participants of this study, I was surprised to learn that she had put off assigning the poster project in her AAR classes for several 
terms. She told me her students had asked her not to do the poster project. Having assigned the poster project several consecutive terms now, the instructor plans to continue to assign it in future terms. Although student learning and motivation are closely tied, things that are unfamiliar can be scary. However, based on this study, the unfamiliarity of the assessment did not prevent students from completing the assignment and doing so with positivity. The majority of the students passed the assessment, and according to the instructor, several students were able to pull up their overall course grade with their project grades. Moreover, several students reported an increase in selfconfidence, and quantitative data revealed that the majority of participants had a positive gain in their attitude toward trying new ways to learn.

Based on the findings of this study, alternative assessments are useful for practicing different levels of learning like application and creation, as several participants reported these as possible learning goals of the poster project. The combined evidence of Lambert (2008) and this study affirm the use, or the need, of instructors to provide students with sufficient support when implementing a new assessment technique, such as real-life examples, a specific rubric, and outlined and clear expectations.

Though it may seem like a small detail, I believe this study also affirms the use of enthusiastic presentation of an alternative assessment or other new way of learning. Cheng and Curtis (2004) linked positive attitudes toward an assessment with the generation of positive washback. In this study, participants were given a positive and enthusiastic presentation of the poster project. Afterward, several participants expressed positivity about the poster project on the pre-test, and most participants had positive 
attitudes after the project was finished. Instructors should keep in mind that their presentation of an assignment or new assessment type can set the tone for how it is received or approached by their students.

Finally, instructors must remember that attitudes are related to beliefs, and those do not change overnight. If students progress from disliking an assessment to feeling indifferent, or even disliking it less, that is a kind of progress. Progress may also look like students enjoying the assessment though still not believing it is a valid assessment measure. For the ESL instructor, an assessment's possible lack of face validity be compensated for in the authenticity of the alternative assessment, as was the case in this study.

\section{Limitations of Study}

Because of the regular mismatch between the quantitative and qualitative results, it may prove useful in a future study to make adjustments to the questions. It is possible that the Likert-scale questions were not able to capture the attitudes of or other beliefs held by the participants. I used a scale of five for the Likert-scale questions: strongly disagree, disagree, neutral, agree, and strongly agree. The limited scale may explain the lack of statistical significance because there was less room for differentiated answers. In a future study, a scale of six would eliminate the option of a neutral response. The number of participants, 24 , was a small sample, and in a future study, it may be more reliable to have a larger sample with more participants from each culture of learning. The fact that I relied on hand-written notes for both the classroom observations and the interview with the instructor was a limitation. I cannot see and hear everything at once. 
Although video-recording a classroom is more invasive, the ability to look back and observe more carefully may uncover findings that went overlooked in this study. Not all the students in the classes used for the context of this study agreed to be participants, so video-recording was not an option.

\section{Suggestions for Future Research}

This study raised questions which would be useful to have answered in future studies. For example, feedback from participants that the text for the AAR course was boring inspired the question, what kind of washback effects do materials have on teaching and learning? If the instructor does not trust the textbook, or if the students think the reading material boring, how will that affect teaching and learning on assessments? Another consideration about materials came up when a student asked about the possibility of preparing a PowerPoint in lieu of a poster, and I began to wonder whether students have had less experience making posters due to their generation and the increased use of technology in the classroom. In a future survey, it may be useful to include a question about participants' experience with a task comparable to the poster project using technology, like a PowerPoint presentation.

Another variable that may be useful to include in a future study is the age of participants. Age can be telling of maturity, but more importantly it can also be telling of how much opportunity a participant has had to encounter different types of assessment. Older students often have more experience with formal education, which may increase their opportunities to encounter different kinds of assessment. 
As previously mentioned, the timing of the course may have affected the data, so it may be interesting to learn whether students respond differently during a Fall or Spring term, instead of Summer. Conducting the study during a Fall or Spring term may also provide a larger and potentially more diverse sample size. This study was conducted in an IEP program, and several participants reported that they expected to have more assignments like the poster project or other presentation later in their university coursework. For this reason, it may be insightful to try a longitudinal study that either follows students after they begin their mainstream academic work, or follow a group of students earlier in an IEP setting as they encounter alternative assessments throughout their program. Attitudes can change slowly, so it may take time to really see evidence of change. But what about non-IEP programs or a non-EAP course? As an instructor in a private ESL school with a mixed demographic of students hoping to transfer to an American university and others who want to improve their English because they plan to live in the United States for any duration of time, I wonder how the implementation of an alternative assessment would be received in a non-academic setting. Because a person's attitudes usually change over time, it may be interesting to do a study with participants who have had more prior experience with alternative assessments and try to elicit information about their early attitudes toward such assessments compared with their attitudes after a few years of experience.

Another timing issue relates to the presentation of the assignment as it may have influenced any initial attitudes the participants had about doing a poster project. The timing of the administration of the pre-test may be key in a future study. In this study, 
the pre-test was administered after the assignment was introduced, however, it may prove interesting to administer the pre-test prior to the first discussion of the assignment, when the idea of doing a poster project is more abstract and less imminent. The attitudes of the participants may be more differentiated if they are not aware that they are about to be assigned a poster project and have not been encouraged by the instructor.

This study aimed to identify and discuss washback effects of an alternative assessment in an EAP class on several dimensions. Although this study was not exhaustive, it revealed some insights into participants' experience with an alternative assessment, namely their attitudes, as well as some important prospects for future research. ESL instructors are encouraged to pursue alternative assessments in the classroom regardless of students' uncertainty and provide their students with sufficient support to manage the assessment and succeed. 


\section{References}

Alderson, J. C., \& Clapham, C. (1995). Assessing student performance in the ESL classroom. TESOL Quarterly, 29(1), 184-187. Retrieved from http://search.proquest.com/docview/85607906?accountid=13265

Alderson, J. C., \& Hamp-Lyons, L. (1996). TOEFL preparation courses: A case study. Language Testing, 13, 280-297.

Bachman, L. F. \& Palmer, A. S. (1999). Language Testing in Practice. Oxford University Press.

Balliro, L. (1993). What kind of alternative: Examining alternative assessment. TESOL Quarterly, 27(3), 558-61.

Brown, J. D., \& Hudson, T. (1998). The alternatives in language asssessment. TESOL Quarterly, 32(4), 653-675. Retrieved from http://search.proquest.com/docview/ 85673728 ?accountid=13265

Burkšaitienè, N., \& Teresevičienė, M. (2008). Integrating alternative learning and assessment in a course of English for law students. Assessment \& Evaluation In Higher Education, 33(2), 155-166.

Cheng, L. (2005). Changing language teaching through language testing: A washback study (Vol. 21). Cambridge University Press.

Cheng, L. \& Watanabe, Y. (Eds.). (2004). Washback in Language Testing: Research contexts and methods. Routledge. 
Cortazzi, M., \& Jin, L. (Eds.). (2013). Researching Cultures of Learning: International perspectives on language learning and education. Palgrave Macillan.

Hafner, A. L. and Ulanoff, S. H. (1994). Validity issues and concerns for assessing English learners: One district's approach. Education and Urban Society, 26(4), 367-389.

Hatch, J. A. (2002). Doing Qualitative Research in Education Settings. State University of New York Press.

Hung, S. T. A. (2012). A washback study on e-portfolio assessment in an English as a Foreign Language teacher preparation program. Computer Assisted Language Learning, 25(1), 21-36.

Ilieva, R. (2001). Living with ambiguity: Toward culture exploration in adult secondlanguage classrooms. TESL Canada Journal, 19(1), 1-16.

Johnson, K. (2009). Second Language Teacher Education: A Sociocultural Perspective. Taylor \& Francis.

Kopriva, R. (2008). Improving Testing for English Language Learners. Taylor \& Francis. Lambert, I. (2008). Assessing oral communication: Poster presentations. Language Research Bulletin, 23, 1-13. Retrieved from http://search.proquest.com/docview/85687131?accountid=13265

McNamara, T. (2006). Validity in language testing: The challenge of Sam Messick's legacy. Language Assessment Quarterly, 3(1), 31-51. Retrieved from http:// search.proquest.com/docview/85658172?accountid=13265 
Messick, S. (1996). Validity and washback in language testing. Language Testing, 13(3), 241-256. Retrieved from http://search.proquest.com/docview/58355879? accountid=13265

Muñoz, A. P. \& Álvarez, M. E. (2010). Washback of an oral assessment system in the EFL classroom. Language Testing, 27(1), 33-49. doi:10.1177/0265532209347148

Nkosana, L. B. (2009). The washback effects of curriculum and assessment reform in Botswana. Marang: Journal of Language and Literature, 19(1), 59-79.

Porto, M. (2010). Culturally responsive L2 education: an awareness-raising proposal. ELT Journal: English Language Teachers Journal, 64(1), 45-53. doi:10.1093/elt/ccp021

Shohamy, E. G. (2001). The Power of Tests: A critical perspective on the uses of language tests. Pearson Education.

Steves, R. (2014). Travel as a Political Act. Avalon Travel.

Suzuki, M. (2009). The compatibility of L2 learners' assessment of self- and peer revisions of writing with teachers' assessment. TESOL Quarterly, 43(1), 137-148.

Teemant, A. (2010). ESL student perspectives on university classroom testing Practices. Journal of the Scholarship of Teaching and Learning, 10(3), 89-105.

Wall, D. (1996). Introducing new tests into traditional systems: Insights from general education and from innovation theory. Language Testing, 13(3), 334-354. doi:http://dx.doi.org/10.1177/026553229601300307 


\section{Appendix A}

Pre-Test

\section{\#1PLEASE DO NOT WRITE YOUR NAME ANYWHERE ON THIS QUESTIONNAIRE!}

A. Please fill in the following blanks honestly. The information you provide will be anonymous.

1. Where is your home country?

2. What is your first language?

3. What is your preferred pseudonym?

4. How are you registered for this class? Circle one: PASS/ NO PASS A-F GRADE AUDIT

B. Circle the best answer about your educational experience in your home country.

1. Have you ever received a grade for making a poster?

YES NOT SURE NO

2. Have you ever received a grade for giving a presentation?

YES NOT SURE NO

3. Have you ever designed a poster by yourself before?

YES NOT SURE NO

4. Have you ever given a presentation by yourself before?

YES NOT SURE NO

5. How often have you experienced alternative assessments?

$$
\text { VERY OFTEN SOMETIMES RARELY NEVER }
$$

C. Circle the best answer about your educational experience in the United States.

1. Have you ever received a grade for making a poster?

$$
\text { YES }
$$

NOT SURE

NO

2. Have you ever received a grade for giving a presentation?

$$
\text { YES NOT SURE }
$$

3. Have you ever designed a poster by yourself before?

YES

NOT SURE

NO

4. Have you ever given a presentation by yourself before?

$Y E S$

NOT SURE

NO 
5. How often have you experienced alternative assessments?

VERY OFTEN SOMETIMES RARELY

NEVER

D. Circle the most appropriate level of agreement based on how you feel about the statements below:

1. I am excited about designing a poster to illustrate a theme from the book I read.

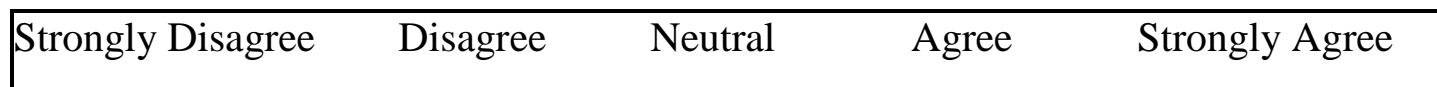

2. I feel comfortable with designing a poster as a way to present information.

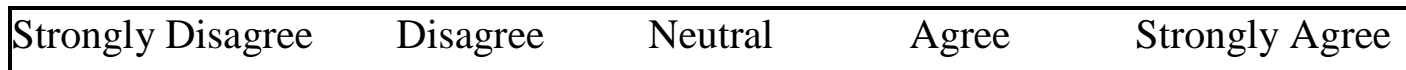

3. I wish I could take a test about the book instead of prepare a poster.

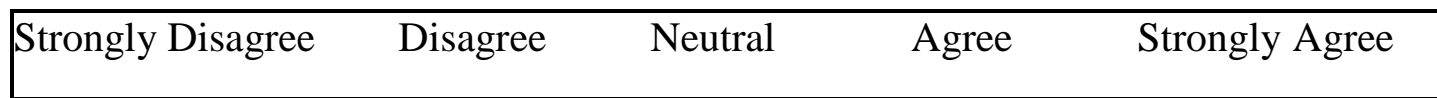

4. I feel like I learn better when I have the chance to use my creative skills.

\begin{tabular}{|c|c|c|c|c|}
\hline Strongly Disagree & Disagree & Neutral & Agree & Strongly Agree \\
\hline
\end{tabular}

5. I like to try new ways to study and learn.

\begin{tabular}{|c|c|c|c|c|}
\hline Strongly Disagree & Disagree & Neutral & Agree & Strongly Agree \\
\hline
\end{tabular}

6. Taking a test is the only way to really know if someone has learned something.

\begin{tabular}{|c|c|c|c|c|}
\hline Strongly Disagree & Disagree & Neutral & Agree & Strongly Agree \\
\hline
\end{tabular}

7. I feel anxious or nervous when I take tests.

\begin{tabular}{|lllll}
\hline Strongly Disagree & Disagree & Neutral & Agree & Strongly Agree \\
\hline
\end{tabular}

8. When I try new ways to learn or to study, it is very hard for me to learn.

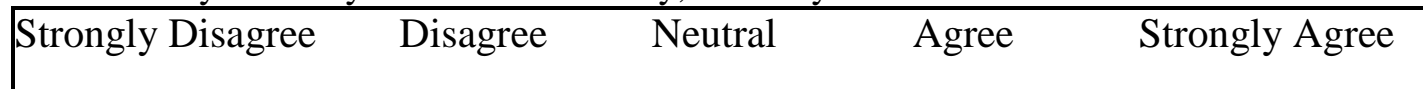

9. In my home country, I always showed my learning by taking a test. 


\begin{tabular}{|c|c|c|c|c|}
\hline Strongly Disagree & Disagree & Neutral & Agree & Strongly Agree \\
\hline
\end{tabular}

10. Tests are not necessarily the best way to see whether someone has learned information.

\begin{tabular}{|c|c|c|c|c|}
\hline Strongly Disagree & Disagree & Neutral & Agree & Strongly Agree \\
\hline
\end{tabular}

11. I do not learn as well when I do creative tasks.

\begin{tabular}{|c|c|c|c|c|}
\hline Strongly Disagree & Disagree & Neutral & Agree & Strongly Agree \\
\hline
\end{tabular}

12. I don't feel comfortable presenting information by designing a poster.

\begin{tabular}{|lllll|}
\hline Strongly Disagree & Disagree & Neutral & Agree & Strongly Agree \\
\hline
\end{tabular}

13. In my home country, I showed my learning by doing something different from taking a test at least one time.

\begin{tabular}{|c|c|c|c|c|}
\hline Strongly Disagree & Disagree & Neutral & Agree & Strongly Agree \\
\hline
\end{tabular}

14. Designing a poster will help me improve my English language skills.

\begin{tabular}{|lllll|}
\hline Strongly Disagree & Disagree & Neutral & Agree & Strongly Agree \\
\hline
\end{tabular}

15. I think I will learn something by designing a poster that I would not learn by taking a test.

\begin{tabular}{|c|c|c|c|c|}
\hline Strongly Disagree & Disagree & Neutral & Agree & Strongly Agree \\
\hline
\end{tabular}

16. To be honest, I don't really know what I am supposed to do for this project.

\begin{tabular}{|c|c|c|c|c|}
\hline Strongly Disagree & Disagree & Neutral & Agree & Strongly Agree \\
\hline
\end{tabular}

17. This assignment is useful because I will need to give presentations in the future.

\begin{tabular}{|lllll|}
\hline Strongly Disagree & Disagree & Neutral & Agree & Strongly Agree \\
\hline
\end{tabular}


18. I don't think I will learn very much from designing a poster.

\begin{tabular}{|c|c|c|c|c|}
\hline Strongly Disagree & Disagree & Neutral & Agree & Strongly Agree \\
\hline
\end{tabular}

19. I feel confident about my ability to design a poster.

\begin{tabular}{|lllll|}
\hline Strongly Disagree & Disagree & Neutral & Agree & Strongly Agree \\
\hline
\end{tabular}

20. This assignment is not useful to me because I do not expect to design posters in the future.

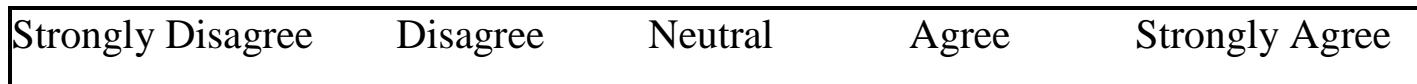

21. Designing a poster is not a good test of my English language skills.

\begin{tabular}{|c|c|c|c|c|}
\hline Strongly Disagree & Disagree & Neutral & Agree & Strongly Agree \\
\hline
\end{tabular}

22. In my home country, I used all of the levels of learning in Bloom's Taxonomy to show my learning in different classes (science, math, language, etc.).

\begin{tabular}{|c|c|c|c|c|}
\hline Strongly Disagree & Disagree & Neutral & Agree & Strongly Agree \\
\hline
\end{tabular}

23. If I had the choice between taking a test and making a poster, I would choose to make a poster.

\begin{tabular}{|c|c|c|c|c|}
\hline Strongly Disagree & Disagree & Neutral & Agree & Strongly Agree \\
\hline
\end{tabular}

24. I don't like that I have to design a poster to illustrate a theme from the book I read.

\begin{tabular}{|c|c|c|c|c|}
\hline Strongly Disagree & Disagree & Neutral & Agree & Strongly Agree \\
\hline
\end{tabular}

25. The instructions for the project were very clear to me. I know what I am supposed to do.

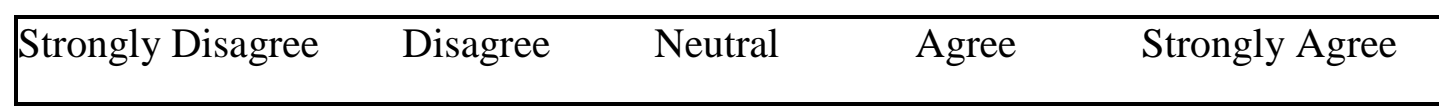


26. My educational experience in my home country did not include all of the levels of learning from Bloom's Taxonomy. (Think of all your subjects.)

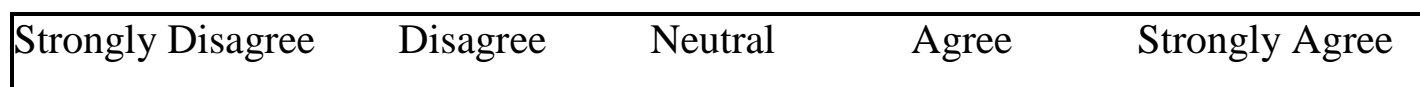

E. Please provide a brief answer to the following questions. Remember, this will not be graded, and your information will remain anonymous.

1. What will you do to prepare this assignment?

2. Will giving a presentation be useful for your learning? How or how not?

3. Describe how you feel about doing this assignment. Would you rather take a test? Why or why not? 
4. What will you learn as a result of this poster project?

5. In your opinion, what is the learning goal for this poster project?

Thank you!

I would like to sincerely thank you for completing this survey. As teachers learn more about how students learn, we can learn how to teach better. 


\section{Appendix B \\ Post-Test \\ \#2PLEASE DO NOT WRITE YOUR NAME ANYWHERE ON THIS QUESTIONNAIRE!}

A. Please fill in the following blanks honestly. The information you provide will be anonymous.

1. Where do you consider your home country?

2. What is your first language?

3. What is your preferred pseudonym?

4. How are you registered for this class? Circle one: PASS/ NO PASS A-F GRADE AUDIT

B. Using the scale below, circle the most honest answer about how you feel about each statement.

1. I enjoyed designing a poster to illustrate a theme from the book I read.

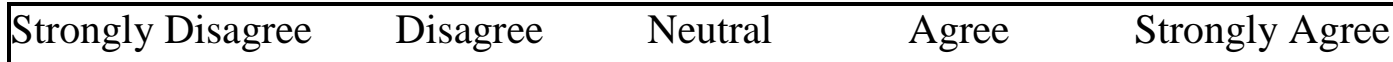

2. I was comfortable presenting my poster to my peers.

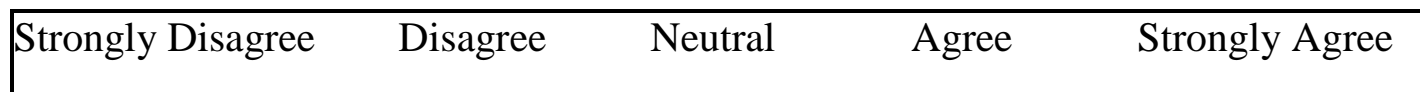

3. I wish I could have taken a test about the book instead of prepare a poster.

\begin{tabular}{|c|c|c|c|c|}
\hline Strongly Disagree & Disagree & Neutral & Agree & Strongly Agree \\
\hline
\end{tabular}

4. I feel I learn better when I have the chance to use my creative skills.

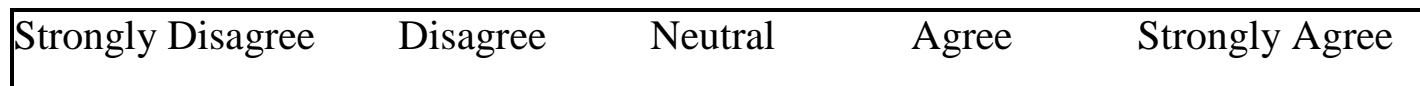

5. I like to try new ways to study and learn.

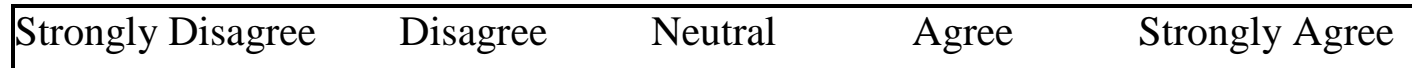

6. Taking a test is the only way to really know if someone has learned something.

\begin{tabular}{|lllll}
\hline Strongly Disagree & Disagree & Neutral & Agree & Strongly Agree \\
\hline
\end{tabular}


7. Presenting my poster to my peers made me feel uncomfortable.

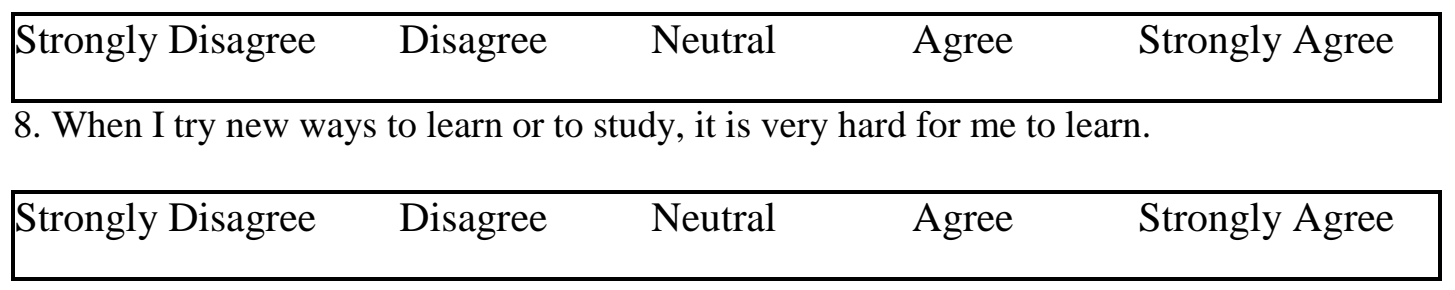

9. Designing the poster was more useful to me than I thought it would be.

\begin{tabular}{|c|c|c|c|c|}
\hline Strongly Disagree & Disagree & Neutral & Agree & Strongly Agree \\
\hline
\end{tabular}

10. I think my poster could have been designed more effectively.

\begin{tabular}{|c|c|c|c|c|}
\hline Strongly Disagree & Disagree & Neutral & Agree & Strongly Agree \\
\hline
\end{tabular}

11. Tests are not necessarily the best way to see whether someone has learned information.

\begin{tabular}{|c|c|c|c|c|}
\hline Strongly Disagree & Disagree & Neutral & Agree & Strongly Agree \\
\hline
\end{tabular}

12. I do not learn as well when I do creative tasks.

\begin{tabular}{|c|c|c|c|c|}
\hline Strongly Disagree & Disagree & Neutral & Agree & Strongly Agree \\
\hline
\end{tabular}

13. In my home country, I always showed my learning by taking a test.

\begin{tabular}{|lllll}
\hline Strongly Disagree & Disagree & Neutral & Agree & Strongly Agree \\
\hline
\end{tabular}

14. I would have learned more in this reading class if I had studied for a test about the book.

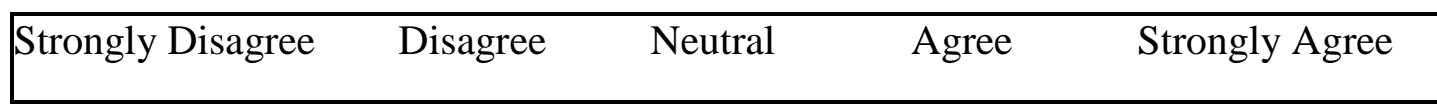

15. In my home country, I showed my learning by doing something different than taking a test at least one time.

\begin{tabular}{|c|c|c|c|c|}
\hline Strongly Disagree & Disagree & Neutral & Agree & Strongly Agree \\
\hline
\end{tabular}


16. Designing the poster allowed me to show my English language ability.

\begin{tabular}{|lllll|}
\hline Strongly Disagree & Disagree & Neutral & Agree & Strongly Agree \\
\hline
\end{tabular}

17. To be honest, I did not understand what I was supposed to do for this project.

\begin{tabular}{|lllll|}
\hline Strongly Disagree & Disagree & Neutral & Agree & Strongly Agree \\
\hline
\end{tabular}

18. Designing the poster was less useful to me than I thought it would be.

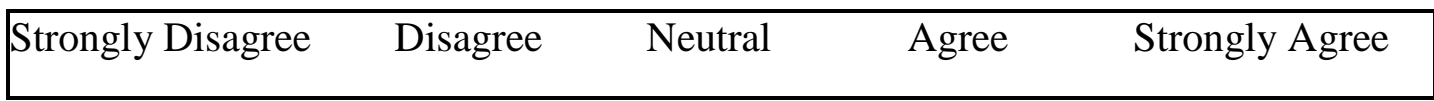

19. I learned something by designing this poster that I would not have learned by studying for a test.

\begin{tabular}{|c|c|c|c|c|}
\hline Strongly Disagree & Disagree & Neutral & Agree & Strongly Agree \\
\hline
\end{tabular}

20. I am confident about how I designed my poster.

\begin{tabular}{|c|c|c|c|c|}
\hline Strongly Disagree & Disagree & Neutral & Agree & Strongly Agree \\
\hline
\end{tabular}

21. The instructions for this project were very clear to me. I understood what I was supposed to do.

\begin{tabular}{|c|c|c|c|c|}
\hline Strongly Disagree & Disagree & Neutral & Agree & Strongly Agree \\
\hline
\end{tabular}

22. My educational experience in my home country did not include all of the levels of learning from Bloom's Taxonomy. (Think of all your subjects.)

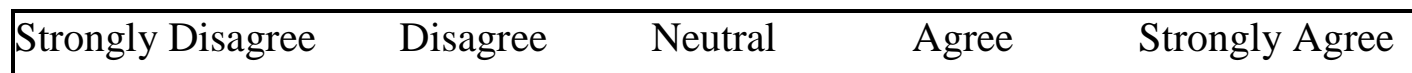

23. If I had the choice between taking a test and making a poster, I would have chosen to make a poster.

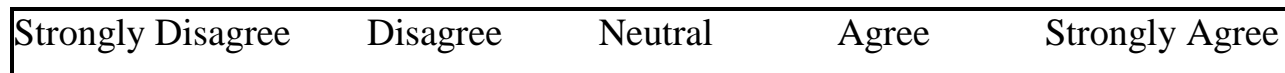


24. I did not enjoy designing a poster to illustrate a theme from the book I read.

\begin{tabular}{llll}
\hline Strongly Disagree & Disagree & Neutral & Agree
\end{tabular}

25. In my home country, I used all of the levels of learning in Bloom's Taxonomy to show my learning in different classes (science, math, language, etc.)

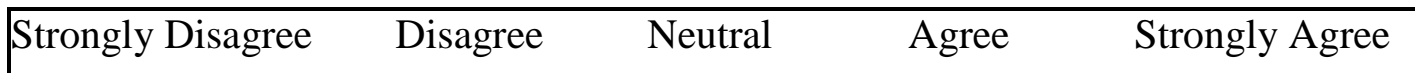

26. Designing the poster did not allow me to show my real English language ability.

\begin{tabular}{|c|c|c|c|c|}
\hline Strongly Disagree & Disagree & Neutral & Agree & Strongly Agree \\
\hline
\end{tabular}

27. Designing the poster was just as useful to me as I expected it would be.

\begin{tabular}{|c|c|c|c|c|}
\hline Strongly Disagree & Disagree & Neutral & Agree & Strongly Agree \\
\hline
\end{tabular}

C. Please provide a brief answer to the following questions based on your opinion. Remember, this will not be graded, and your information will remain anonymous.

1. Describe your experience preparing for your presentation including designing the poster. In other words, what was it like designing the poster? What did you do? How long did it take? How did you feel?

2. Did you learn something from doing this assignment? If so, what? 
3. In the future, how would you feel about designing a poster to present information?

4. Has your attitude about this poster project changed in any way? If so, how?

5. In your opinion, what was the learning goal for this poster project?

\section{Thank you!}

I would like to sincerely thank you for completing this survey. As teachers learn more about how students learn, we can learn how to teach better. 


\section{Appendix C \\ Instructor's Interview Questions}

\section{Questions for Interview with Instructor}

1. Did students ask you questions about the poster project after class or during your office hours?

2. What kinds of questions did students ask?

3. Why do you think students asked those questions or had those concerns?

4. How did you address those questions?

5. How did the students react to the explanation you gave them?

6. Were there questions asked that made you consider revising your instructions for the assignment? If so, can you describe an example?

7. Having administered this project $x$ number of times, have you noticed a change in the apparent attitudes of students toward the assessment? In the quality of the posters?

8. Have you noticed whether students who ask questions, or brainstorm with you, perform better on the assessment?

9. Do you ever bring the questions asked by individual students into the class at large?

10. What kinds of modifications have you made to the project or its instructions over the years?

11. What do you perceive the biggest value to be for your students' learning as a results of this assessment?

12. Do you students ever give you feedback about this project after the class? If so, what kind of feedback do they give you?

13. Did students give you any feedback at the end of this class this term?

14. Do you plan to conduct this assessment the next time you teach this class?

15. Is there anything you would like to share related to this assessment? 


\section{Appendix D \\ Assignment and Rubric}

\section{Travel as a Political Act - Poster Presentation Assignment}

\section{Purpose:}

To assess students' ability to apply themes from a full-length non-fiction text to familiar experiences or areas of interest using accurate, academic English.

\section{Task:}

Each student will prepare a poster to present at a joint session of AAR classes. At the poster session, students will present and discuss the material on their poster. Students will also rotate and view and ask questions about the posters of fellow students.

\section{Poster Title}

“Traveling Politically in __ "

\section{Steps to complete the assignment}

1. Choose a location. It can be a city, region, state, or country. It can be a place you come from, a place you have visited, or a place you are interested in and would like to research.

2. Compile materials, artifacts, pictures, maps, quotes, and any other sources of information that illustrate a connection between the location you have chosen and concepts from Travel as a political act. Focus on the guidelines Rick Steves gives in Chapter 1.

3. Purchase a poster (flat or tri-fold) and organize your information professionally, creatively, and effectively on your poster.

4. Prepare ideas for orally explaining the links between your location and TAPA. You should plan to speak for approximately 5 minutes.

5. Attend the poster session. It will be set up like a conference. You will present your poster several times and have a chance to visit others. Interact with your classmates, peers, and guests. 
Suggestions:

- Cite any sources of information (websites, people, books, etc.)

- Include quotes from locals.

- Present timelines or other charts to explain historical information.

- Use illustrations or pictures.

- Describe and explain cultural values and perspectives.

- Reveal potentially negative aspects (as a jester might)

- Include essential historical information and explain its significance to current events.

- Cite statistics that introduce economic or demographic information.

- Explain how the society/community has come up with 'alternative' solutions to problems that are different from our own.

- Offer evaluations (your own or from others'...negative or positive).

A few questions to think about:

- Would travelers need to overcome any fear to visit this place?

- Who lives in this place? What is their lifestyle like?

- What aspects of life in this place may interest or even amaze your audience?

- What policies are different from the ones your audience knows well?

- If someone were traveling 'thoughtfully', what would be a reason to visit this place?

- What would Rick Steves say about the location? 


\section{Poster Presentation Grade - Advanced Academic Reading}

\section{Name:}

Content focus

\begin{tabular}{|l|l|l|}
\hline \multicolumn{1}{|c|}{ C } & \multicolumn{1}{|c|}{ B } & \multicolumn{1}{c|}{ A } \\
\hline $\begin{array}{l}\text { The topic of the poster } \\
\text { corresponds to a topic from } \\
\text { the text but is very general. }\end{array}$ & $\begin{array}{l}\text { The topic of the poster corresponds } \\
\text { to a topic/theme from the book and } \\
\text { has been narrowed or focused. }\end{array}$ & $\begin{array}{l}\text { The topic of the poster } \\
\text { corresponds to a topic/theme } \\
\text { from the book, is well-narrowed, } \\
\text { and demonstrates clear analysis. }\end{array}$ \\
\hline
\end{tabular}

Sources of information

\begin{tabular}{|c|c|c|}
\hline $\begin{array}{l}\text { The information provided } \\
\text { comes from one source } \\
\text { (book, article, interview, } \\
\text { own experience) }\end{array}$ & $\begin{array}{l}\text { The information provided comes } \\
\text { from 2 sources. }\end{array}$ & $\begin{array}{l}\text { The information provided comes } \\
\text { from more than 2 sources. }\end{array}$ \\
\hline C & B & A \\
\hline
\end{tabular}

Visual presentation

\begin{tabular}{|c|l|l|}
\hline $\begin{array}{l}\text { The organization of the } \\
\text { information on the poster is } \\
\text { messy or very simple. }\end{array}$ & $\begin{array}{l}\text { The organization and presentation } \\
\text { of the materials on the poster is } \\
\text { easy to follow and clean. }\end{array}$ & $\begin{array}{l}\text { The presentation and } \\
\text { organization of materials on the } \\
\text { poster enhances the analysis of } \\
\text { concepts and is professional. }\end{array}$ \\
\hline C & B & A \\
\hline
\end{tabular}

Oral presentation

\begin{tabular}{|c|c|l|}
\hline $\begin{array}{l}\text { The oral presentation } \\
\text { consists mainly of reading } \\
\text { information on the poster. }\end{array}$ & $\begin{array}{l}\text { The oral presentation adds some } \\
\text { information to the poster. }\end{array}$ & $\begin{array}{l}\text { The oral presentation } \\
\text { significantly enhanced the } \\
\text { analysis presented on the poster. }\end{array}$ \\
\hline C & B & A \\
\hline
\end{tabular}


Creativity and level of originality

\begin{tabular}{|l|l|l|}
\hline $\begin{array}{l}\text { The poster illustrates an } \\
\text { idea or theme from the text. }\end{array}$ & $\begin{array}{l}\text { The poster demonstrates a new } \\
\text { way of thinking/viewpoint on a } \\
\text { topic. }\end{array}$ & $\begin{array}{l}\text { The poster demonstrates original } \\
\text { thought, creativity, and a deeper } \\
\text { lillustrate the theme. } \\
\text { level of analysis and synthesis } \\
\text { than previously discussed in } \\
\text { class or in earlier assignments. }\end{array}$ \\
$\begin{array}{l}\text { The information had been } \\
\text { discussed previously. }\end{array}$ & More than one medium is used. & More than one medium is used. \\
\hline C & B & A \\
\hline
\end{tabular}

Overall grade: 


\section{Appendix E \\ Pre-Test Open-Ended Responses}

The following are the open-ended questions from the pre-test with their corresponding responses from participants.

\section{What will you do to prepare this assignment?}

$\underline{\text { Saudi Arabia }}$

1. I will think what my country's culture and I will [connect] with our book.

2. I should choose topic that I like, and I should give myself time to do that.

3. I will choose a country or city that I know well.

4. I will think about some narrow topic to start. I will try to find or think about my experience to connect between them. (pictures, quotes)

5. Choose topic for my [assignment] then decide what I will need to prepare my assignment.

6. Blank

7. I will find the place which I going to talk about.

8. I'm going to read the chapter that I want to talk about and I'm going to get some an important information and I'm going to organize it.

Chinese-Speaking Countries

9. I will choose one specific place to prepare.

10. read book. find information and picture

11. search information in the book or online

12. Check info from internet, design the form that may clear to explain my opinion, book info

13. Research

Libya

14. I think I will gather some information from the internet, some [?] sources, and quotation from books. 
15. I will search on the internet about the ideas which I will use and take some information from people who have knowledge about my theme.

16. I will read about the topic that I choose before from the internet to know more and more, and I have to find at least two sources to present it on my poster. After that, I have to find some pictures and what the structure that I need to put in.

17. First, I need to pick a topic from the book then I should apply that topic on one of the countries. After that, I should relate that topic to one of Steves' recommendations.

$\underline{\text { Brazil }}$

18. Make a plan of what I'm going to put on the poster and how I will present it.

19. I pretend to prepare an infographic about Rio De Janeirois gentrification processes.

20. I will search at the Internet and talk with my friends.

21. I will make a research, read my notes, and apply the information of the book "TAPA" to do the poster.

$\underline{\text { Kuwait }}$

22. Collect more information about my topic, read the chapter, or the part that related to my project, and ask my friends to have different answers.

23. Blank

24. I will choose one of the countries that I have visited before and try match what I have learned from Steves to my trip and create a question and theme for my assignment.

\section{Will giving a presentation be useful for your learning? How or how not?}

$\underline{\text { Saudi Arabia }}$

1. Blank 
2. Yes, I am. When I give a presentation, I show what I learn from speaking and contect with other person.

3. Yes, I think it is useful because when I get to the university, I would do a lot of presentations.

4. Yes, because I will do something new, so I will learn something might be helpful for my future, improve my speaking/language.

5. I think giving presentation always be useful for the learning because I have to find sources for my presentation and this will help me when I want to find sources for my researches. This just one examples.

6. Yes, it gives me the [confidence] to speak and reach the information to the audience.

7. No, I think the test not fair. I'm not good at speaking English as when I'm reading or writing. Also we are take reading classes.

8. I think this is an old style learning I mean this is can help students in the beginning of the new language not in level 5!!

\section{Chinese-Speaking Countries}

9. Yes. I think so. Because it's good chance to learn and develop my English language skills.

10. Yes. It will built my confident to speak English

11. To be honest, I don't know if this will be useful for my learning. I just follow what teacher says.

12. Yes. In regular class, almost every [professor] will give student group work and presentation so, I think practice presentation is useful for future.

13. I don't really agree with this.

Libya

14. When I will give my presentation, I will improve my speaking skills. Also, I will improve my listening when listeners ask me. 
15. In some ways could be helpful from me because while I'm doing the poster, I will try to clarify my ideas for people who don't know my poster. Thus, I will get the chance to see my ability for trying to illustrate my ideas.

16. I think it is useful in many ways, for example, you can get more information from the internet, so you can learn more, and you will listen to other people present, and that may make you better to understand many things that you couldn't understand it.

17. Yes, it will be useful for me to give a presentation I believe that speaking English fluently can be improved by giving presentations and answering the questions that are asked by the audience. Brazil

18. It'll be useful, because I'll need to use all aspects of Bloom's Taxonomy.

19. Yes, it will. As a graphic design student, I strongly believe that visual communication is important to a better comprehension of any subject.

20. Yes, because it will make me practice public speaking.

21. Yes, I think the presentation is a good way for learning and I will need this skill not only in the future but also every day that I express my opinion.

Kuwait

22. Yes, it makes me more fluent and confident in English.

23. Well, it will help indirectly on my self-confidence.

24. Yes. Because when I will give presentation, I have to prepare well and cover everything to present it clearly, Also by preparing I will be able to answer questions so it will be useful.

\section{Describe how you feel about doing this assignment. Would you rather take a test? Why or} why not?

$\underline{\text { Saudi Arabia }}$ 
1. Ifeel [confused] because I didn't understand this assignment clearly. No, because I don't like to take a test and I really don't like this book.

2. I felt more comfortable. No, I am not because the test did not give you what learn [exactly].

3. I would like to do this assignment to improve my grade.

4. I don't know because I did not [decide] yet what I will [write] about, but it's good and new way of assignment which is make me excited to do it.

5. Posters are built on creating and tests are built in understand and remember. I prefer understanding than creating.

6. Ifeel nervous about it because the book that in reading is so boring for me. No, I wouldn't take a test.

7. Yes, test is more fair than project. The one who speaks good they take a good grade.

8. I would rather take a test because I think I'm going to do better in the test than in the poster. however, I feel a little bit confused but it will be easy.

\section{Chinese-Speaking Countries}

9. I feel this assignment is better than taking a test. Because taking a test will give us stressure and feel boring.

10. [nervous]. I focus on grade.

11. I don't care. However, I have both in this term. I just want to do one of these.

12. I'd like to do the presentation or poster!!! I really do like paper test, but some subjects need it.

13. It's too complicated.

Libya

14. I feel comfortable because I don't have to write or study a specific thing. I will prepare what I have to say. 
15. I feel not good actually because I don't have many information yet.

16. I would like to take a test rather [than] doing a presentation because I don't like to speak in front of people who watch me.

17. Actually, I really like the notion that we apply our understanding of a theme by doing a poster as I don't prefer that my understanding will be tested by doing a test. By doing the poster, my understanding will enhance and will be more fun.

Brazil

18. Ifeel very comfortable doing this assignment, because is something different. When you like what you're doing you learn more.

19. I feel confident and I'd rather to this assignment than a test. Because English is not my first language then I like to have more time to write and to review the assignments.

20. I'm not really motivated, maybe because of the high volume of homework from all classes. I think a test would be easier.

21. A test, sometimes, when well elaborated can cover the same area of the knowledge of the poster. I think the main difference is in the presentation.

Kuwait

22. This is better than tests. Tests make me nervous.

23. I would rather taking a test because I don't think that make a poster can help me learn more. 24. I'm excited to do it because I didn't do it before and I'm ready to take it as a challenge and new experience and learn something new. I think test and presentation are different than each other. 


\section{What will you learn as a result of this poster project?}

$\underline{\text { Saudi Arabia }}$

1. I don't know.

2. Blank

3. showing my way to present some info.

4. I will learn how to organize the information and connect with them, also [write] about new experience.

5. New experiences!

6. Blank

7. I'm not sure.

8. I'm going to learn how to be more confident but this is I think will help more with students in level 1, 2, 3, in my opinion

\section{Chinese-Speaking Countries}

9. I will learn more about how to be a good speecher.

10. I don't know, but I think it is similar to presentation.

11. Blank

12. How to introduce my opinion clearly on a paper! What is the major or main idea I need to focus! It can help to clarify our mind.

13. Understanding much deeper

Libya

14. I will learn how to present better.

15. How to illustrate my ideas to my classmates.

16. I think that I may learn more and more about my country where I decide to present in the class. 
17. First, I will learn more about the presented topic. Second, doing the poster can make me more confident in speaking and interducing my belief and understanding. Finally, doing the poster can give me the chance to show my creativety in interducing my ideas.

Brazil

18. I'll learn how to organize, evaluate and create ideas to be presented in this assignment. Also, I'll improve my speaking skills.

19. It will be my first attempt to design an infographic, so I hope to develop skills about [how] to transform data into visual information with coherence.

20. Public speaking

21. Learn how to improve presentation skill [and] learn to apply an information Kuwait

22. Presenting, speaking, and applying information.

23. Improving my creativity

24. I will learn how to apply what I learned from a book to a poster.

\section{In your opinion, what is the learning goal for this poster project?}

Saudi Arabia

1. I think the goal how we can connected our idea with other sources.

2. Blank

3. I don't have an idea.

4. The goal of this poster I think to know how student can connect the information from the book and his/her experience. Also, to know how they can speak and understand.

5. To learn how to create and how give a speech rather give [presentation].

6. I want to be more educated and more understanable. 
7. I think may help understand more than before.

8. Actually, I want to learn more how to organize a poster and I'm going to try learn new information that may help me.

Chinese-Speaking Countries

9. The goal for this poster project is to develop our English language better. To do more chances to do presentation.

10. Get high grade, and an oppertunity to practice speaking.

11. Maybe, practicing my English logical

12. Set confidencial on public speaking, apply with knowledge that we learned to created [something] belong to us, practice presentation, [and] help community.

13. Blank

Libya

14. I think the goal is to improve our speaking skills and to have confident when someone presents in front of many people.

15. Doing the Bloom's Taxonomy which means doing remember, [analyze], etc. in one assignment.

16. In my opinion, I think that this poster project's goal is to know more and more how to travel politically not to travel for excitements. That's all.

17. I think improving the ability in giving presentations is the first goal. In addition, exchange some understandings and knowledge about different topics between our classmates.

$\underline{\text { Brazil }}$

18. To see if students can use Bloom's Taxonomy fluently.

19. The learning goal is to develop skills related to Bloom's Taxonomy.

20. Public speaking and the use of a source to compare. 
21. Apply the concepts

Kuwait

22. To apply our experiences, thoughts to what we have learned from the book.

23. Blank

24. To show that I understand and able to apply what is in a book onto a poster or anything else. 


\section{Appendix F \\ Post-Test Open-Ended Responses}

The following are the open-ended questions from the post-test with their corresponding responses from participants.

Describe your experience preparing for your presentation including designing the poster. In other words, what was it like designing the poster? What did you do? How long did it take? How did you feel?

$\underline{\text { Saudi Arabia }}$

1. I didn't like designing the poster because it is very hard, and it spend a lot of time. I think I did well, but I really was afraid. I taken 6 hours or more for the poster.

2. Blank

3. It was easy. I didn't spend much time on it. I just did it in the night before. I feel like I would have done better if I spend some time on it.

4. First, it was little hard to think about something from my experience and connected with Steves recommendation but, later I feel so excited to start my presentation. My teacher help me to be proud when I talking about my poster. This make me more comfortable about it. 5 min.

5. Blank

6. Blank

7. It's take 5 hours, I feel [nervous], I don't understand.

8. Actually, the presentation is easy but sometimes it makes the students [lose] some points because they did not [prepare] for it. So I think the presentation is easy for me and I feel comfortable with it.

Chinese-Speaking Countries

9. When I prepared my poster. I just thought about my topic, researched my topic and looked for information. 
10. need picture and world. Should be clear to help people understand. put key words and relative picture 5 or more hours. just so-so, but it is more interest [than] test.

11. It took about two days.

12. I take almost 2 hours to design my poster. I feel very good and I want show more information to listener. I like poster presentation than take test.

13. I did a lot of research. I did it for one day. I was satisfied my poster.

Libya

14. It was easy to make a poster. I did some pictures, charts, and texts. It takes from me one hour and half, and I felt comfortable about it.

15. Blank

16. Designing poster was easier that I expected. I was wonder what I had to do in the first time, but after I chose the country and the topic, it became so easy for me to find the information. 17. At first it was really hard for me to get the idea of how I should structure my poster, but when Ifound the idea, everything was easy for me. It took me two days to complete my poster.

Brazil

18. Designing the poster was very interesting, albeit my poor abilities to drawn. I talked about the city I came from. The whole preparation took me one day.

19. It was a good experience. I did a postal card from my hometown showing natural beauties, cultural heritage, social inequalities, and gentrification processes. It took almost 12 hours: $8 \mathrm{~h}$ of planning and $4 h$ of execution.

20. It didn't take time to prepare the poster, the most beneficial part is to think about a subject and how to tell a story.

21. I used a computer program to help me organize the poster. I took about 5 hours. Ifelt comfortable with the results. 
Kuwait

22. It was fun designing a poster which presented my home country. It took an hour. Ifeel proud and happy.

23. Unfortunately, I didn't do a poster.

24. 1) I choose the country.

2) Though about the main things (according to Steves: religion, people, places, history)

3) Search for useful info

4) Design the poster (less than 2 hours)

5) Learned new things

\section{Did you learn something from doing this assignment? If so, what?}

Saudi Arabia

1. I did learn any thing because I notice everyone did the poster for taking good grade, and they didn't explain clear.

2. Yes, I learn how I designs.

3. It was nice to do this assignment because I can shear some info about my culture.

4. Yes, because it is something new, I did not have any poster in my classes before. I learn something new, and I really like it.

5. Blank

6. No.

7. No

8. No, just designing

Chinese-Speaking Countries

9. Yes. I think that I have learned how to make a poster and improve my speaking skill. 
10. Yes. I know more information out of book. I know a country and I know how to travel political.

11. Blank

12. Yes. I think I practiced my presentation. Also, I learned some knowledge about my topic.

13. know much deep from this topic

Libya

14. I learn that when our present a poster, you increase the ability of your English skills.

15. Yes, I got new ideas because I was looking for information on the internet.

16. I learned how I can reach my idea to other student easily by putting some pictures, phrases, etc. I think this poster is very useful.

17. Yes, I learned how to be creative in making my ideas clear and explicit. Additionally, the poster project improved my ability to do a presentation.

$\underline{\text { Brazil }}$

18. Yes, I did. I learned some characteristics from the city I came from that I did not know.

19. Yes. I learned more about gentrification processes.

20. Yes, I learned how to apply "Travel as a Political Act" to my reality.

21. Yes, I used a computer program that could be very useful in other activities, and I learned to organize my poster.

Kuwait

22. Yes, apply what I have read and studied in TAPA to my presentation.

23. [Did not do a poster.]

24. Yes, applied what I have learned from Steves [and] how to design a poster. 


\section{In the future, how would you feel about designing a poster to present information?}

\section{$\underline{\text { Saudi Arabia }}$}

1. I think I feel the same as this poster.

2. Blank

3. It is ok for me. I wouldn't see it difficult.

4. I would feel more excited to make search and information with my reality.

5. Blank

6. It's not big deal for me.

7. I will be angry when I have like this test

8. I'm not going to feel a new feeling because I had done it before so I think it's a normal assignment.

\section{Chinese-Speaking Countries}

9. I think it's a good way to create something from what we learn from the class.

10. I don't know. If it is a homework, I will do.

11. Blank

12. I feel designing a poster to present is a good way to check the knowledge.

13. I will do more for next time.

Libya

14. I would feel happy because it is a good thing that we try a new ways to learn.

15. I will feel good because it would be easier than the first time.

16. I think that I can do a poster very easy, and I can do a great job.

17. I would feel more comfortable and confident because it will not be the first time to design a poster. 
$\underline{\text { Brazil }}$

18. I'd feel comfortable.

19. Ifeel comfortable!

20. I would not like, but is better than test.

21. Much more comfortable, it will be easier to do that.

Kuwait

22. I'll go for it.

23. I would be encouraged to show my ability to other people.

24. Easy and helpful

Has your attitude about this poster project changed in any way? If so, how?

$\underline{\text { Saudi Arabia }}$

1. Blank

2. Blank

3. Not at all.

4. Yes, first I feel [scared] to fail or can't do it but, then I like the idea of our poster.

5. Blank

6. No

7. No

8. No

\section{Chinese-Speaking Countries}

9. No, I haven't.

10. No, I don't think I have any change.

11. Blank 
12. No, I hasn't.

13. No

$\underline{\text { Libya }}$

14. I don't think so.

15. Yes, I thought that it would an useful experience, but then I realized that it was good from me to grow up in my skills.

16. It changed a little bit because I was thinking that it was very hard, but I was wrong.

17. Somewhat yes, I thought that [designing] a poster will not be fun, but now I enjoyed it.

$\underline{\text { Brazil }}$

18. No

19. No. I always have a positive attitude about this assignment.

20. No

21. Yes, the organization

$\underline{\text { Kuwait }}$

22. No

23. Yes, I thought it's useless and has nothing to do in my subject but I found the [opposite\}. I wished that I did the poster.

24. Yes, easy, no stress.

In your opinion, what was the learning goal for this poster project?

$\underline{\text { Saudi Arabia }}$

1. I think the goal is helping the student to get more information about the book.

2. Blank

3. To see you ability to commber some of the info that Rick Steves talked about in his book to the poster. 
4. to find way to connect our experience with information from the book that we already read.

5. Blank

6. It was how to present my poster.

7. to see we understand the book or not.

8. Maybe to see the student if they understand the book they had read or to make the student well prepared to present any poster in future.

\section{Chinese-Speaking Countries}

9. I think that this poster project in order to train our presentation skills and let us learn creative from the textbook.

10. Helping us understand our class. How to use in the life and help us study.

11. Blank

12. Use the knowledge from book to our life.

13. gots more grade

Libya

14. The goal was to make sure that everyone has confident in his/herself to present their information.

15. Apply Bloom's Taxonomy in one project.

16. In my opinion, I think that the goal is to connect what you learn from the book with your experience or your opinion, so you can create a good picture to your opinion.

17. First, I think for testing our ability to understand the book is better by doing a poster as it will make us memorize what we have learned.

Brazil

18. The apply Bloom's Taxonomy effectively

19. The learning goal was to apply our critical thinking skills to different cultures. 
20. Apply.

21. Apply the information of the book in our life, with our own experience.

Kuwait

22. Applying

23. To search by reading something we want, so it's combined between fun and learning.

24. How to present what we learned in new way 